\title{
Animal models of mitochondrial DNA transactions in disease and ageing
}

\author{
Marcos T. Oliveira ${ }^{1}$, Rafael Garesse ${ }^{2}$, and Laurie S. Kaguni ${ }^{1, *}$ \\ ${ }^{1}$ Department of Biochemistry and Molecular Biology, Center for Mitochondrial Science and \\ Medicine, and Graduate Program in Genetics, Michigan State University, East Lansing, MI \\ 48824-1319, USA \\ 2Departamento de Bioquímica, Instituto de Investigaciones Biomédicas "Alberto Sols" CSIC- \\ UAM, Biomedical Network Research Centre on Rare Diseases (CIBERER), Facultad de \\ Medicina, Universidad Autónoma de Madrid, Arzobispo Morcillo 4, E-28029 Madrid, Spain
}

\begin{abstract}
Mitochondrial DNA (mtDNA) transactions, processes that include mtDNA replication, repair, recombination and transcription constitute the initial stages of mitochondrial biogenesis, and are at the core of understanding mitochondrial biology and medicine. All of the protein players are encoded in nuclear genes: some are proteins with well-known functions in the nucleus, others are well-known mitochondrial proteins now ascribed new functions, and still others are newly discovered factors. In this article we review recent advances in the field of mtDNA transactions with a special focus on physiological studies. In particular, we consider the expression of variant proteins, or altered expression of factors involved in these processes in powerful model organisms, such as Drosophila melanogaster and the mouse, which have promoted recognition of the broad relevance of oxidative phosphorylation defects resulting from improper maintenance of mtDNA. Furthermore, the animal models recapitulate many phenotypes related to human ageing and a variety of different diseases, a feature that has enhanced our understanding of, and inspired theories about, the molecular mechanisms of such biological processes.
\end{abstract}

\section{Keywords}

mtDNA replication; mtDNA repair and recombination; mitochondrial nucleoids; mitochondrial transcription; animal models; mouse; Drosophila

\section{Introduction}

In animals, the mitochondrial DNA (mtDNA) is a small, compact, circular molecule that encodes 13 essential polypeptides, all of which are subunits of the mitochondrial oxidative phosphorylation system (OXPHOS). Animal mtDNA also encodes the RNA components of the mitochondrial translational system, which include 22 transfer RNAs and 2 ribosomal RNAs (Figure 1). As with all genetic material, the information encoded in mtDNA must be read and interpreted correctly for proper function of the eukaryotic cell, and transmitted

(C) 2010 Elsevier Inc. All rights reserved.

"Corresponding author. Telephone: +1 517353 6703. Fax: +1 517353 9334. 1skaguni@msu.edu.

Publisher's Disclaimer: This is a PDF file of an unedited manuscript that has been accepted for publication. As a service to our customers we are providing this early version of the manuscript. The manuscript will undergo copyediting, typesetting, and review of the resulting proof before it is published in its final citable form. Please note that during the production process errors may be discovered which could affect the content, and all legal disclaimers that apply to the journal pertain. 
accurately as these cells and whole organisms reproduce. These processes, comprising the initial stages in mitochondrial biogenesis, involve mtDNA replication, repair, recombination and transcription, and are defined herein as mtDNA transactions. The factors required for these transactions (Table 1), along with $\sim 1500$ other polypeptides found in the mitochondrion, are encoded by the nuclear DNA (Wallace 2005) and when their genes are mutated, absent or overexpressed they may cause severe mitochondrial dysfunctions, leading to diseases and ageing. Despite rearrangements in the order of the genes encoded in the mtDNA are commonly found in different animal taxa (Boore 1999), the overall structure and gene content of the genome and the proteins required for mtDNA transactions are largely conserved, offering scientists the opportunity to use animal models to understand mitochondrial biology and medicine.

Links between mitochondrial dysfunction and human disease-related states and with ageing have become increasingly more evident in the last few years as research on cancer, diabetes, neurodegenerative disorders and premature ageing progresses (Wallace and Fan 2009). Interestingly, many mitochondrial disorders exhibit a delayed onset and progressive course, and result in many of the same clinical manifestations that are observed in age-related diseases (Druzhyna et al. 2008). This and other data lend support to the mitochondrial theory of ageing (Harman 1972), which states that reactive oxygen species (ROS) generated by mitochondrial OXPHOS can cause damage to various macromolecules and primarily, mtDNA. Mutated mtDNA will encode defective OXPHOS polypeptides, subsequently leading to increased ROS levels and oxidative damage, and creating a vicious cycle that ultimately leads to lifespan limitation. Although this theory is not supported completely by some recent experiments (discussed in this review), it is easy to understand the importance of the proteins involved in mtDNA transactions. Maintenance of the integrity of mtDNA and its expression is paramount in maintaining healthy mitochondria and ultimately, healthy organisms.

In this review, we will focus on the nuclear-encoded factors required for mtDNA replication, repair, recombination and transcription and on consequences to mtDNA, mitochondria and the whole organism when the expression of these proteins is altered or variant proteins are expressed instead. For this purpose, scientists have taken advantage of powerful animal and cell culture models, giving special attention to the mouse and the fruit fly, Drosophila melanogaster. These models have helped to demonstrate that OXPHOS defects have broad relevance to the genetics, biochemistry and physiology of human diseases, and to the ageing process (Wallace 2008). We acknowledge that all mtDNA transactions take place in the context of nucleoprotein complexes called mitochondrial nucleoids, but we will not discuss nucleoid organization and its dynamics in this review; rather, we refer the reader to recent papers by Bogenhagen (2009) and Wallace and Fan (2009).

\section{2. mtDNA replication}

The field of mtDNA replication has experienced a recent expansion as a result of several key findings. First, mutations in the human genes encoding three of the four known constituents of the mtDNA replication fork (Figure 2), the catalytic and accessory subunit of pol $\gamma$, pol $\gamma$ $\alpha$ and $\beta$, respectively (review in Copeland 2008), and the mtDNA helicase (Spelbrink et al. 2001), have been found in association with the human diseases progressive external ophthalmoplegia (PEO), Alper's syndrome, and ataxia-neuropathy. These are associated with mtDNA depletion and/ or accumulation of mtDNA point mutations and deletions, and manifest with neurological and/ or muscular problems due to mitochondrial dysfunction. Second, the development by Jacobs, Holt, and co-workers of the two-dimensional agarose gel electrophoresis (2DAGE) procedure, applied in association with various nucleic acidmodifying enzymes to analyze mtDNA replication intermediates (RIs), has prompted new 
models for vertebrate mtDNA replication that differ from the traditional strand-displacement model that has been studied by Clayton and co-workers for over 30 years. Though some controversy has been generated as a result (Bogenhagen and Clayton 2003a, b, Holt and Jacobs 2003), it seems reasonable that the numerous models for mtDNA replication that populate the current literature may be a reflection of the different modes that operate in vivo, and represent adaptive processes to ensure appropriate mtDNA copy number and mitochondrial gene expression, and hence ATP production via OXPHOS. Thus, a brief explanation of the current models may help the reader to understand the new findings obtained from whole animal and cell culture models.

The original model of mtDNA replication derives from electron microscopy and end mapping of mtDNA purified by equilibrium sedimentation in cesium chloride density gradients (Clayton 1982). In this model, the synthesis of the mtDNA leading strand (known as the heavy strand in vertebrate mtDNA because of its guanine-rich composition) initiates within the non-coding region at a site designated as $\mathrm{O}_{\mathrm{H}}$ (see figure 1), and proceeds continuously. When leading strand synthesis reaches about two thirds of the distance around the mtDNA genome, the origin of the lagging strand (the light strand in vertebrate mtDNA) synthesis $\mathrm{O}_{\mathrm{L}}$ is exposed and replication of the lagging strand is initiated and synthesis proceeds continuously. The overall process is thus unidirectional, continuous and asymmetric. In contrast, studies using 2DAGE (Holt et al. 2000, Reyes et al. 2005, Yang et al. 2002, Yasukawa et al. 2006, among others) have revealed evidence for bidirectional replication and fully DNA theta replication intermediates indicative of coupled leading and lagging DNA strand synthesis, as in nuclear and bacterial DNA replication. Furthermore, a new class of RIs was discovered: extensive segments of RNA were found incorporated on the lagging strand, giving rise to the RITOLS (RNA Incorporated Throughout Lagging Strand) model. This model also implies strand-coupled replication with the RNA RIs subsequently being maturated into DNA. Though in this case, replication appears to proceed unidirectionally. Because no primase activity has been detected in the mtDNA helicase (Farge et al. 2008, Matsushima and Kaguni 2009), a homologue of the bifunctional bacteriophage T7 gp4 primase-helicase, it is believed that the RNA RIs of the RITOLS model, and likely the RNA primers in the theta and strand-displacement models, are generated by the transcriptional machinery of the mitochondrion (discussed below).

Perhaps the strongest contribution of the development of the 2DAGE technique to mtDNA has been its application to studying replication in vivo when the activities of pol $\gamma$, mtDNA helicase, or other protein involved in mtDNA transactions are compromised. In a study by Wanrooij et al. (2007), human HEK293 Flp-In ${ }^{\mathrm{TM}} \mathrm{T}-\mathrm{REx}^{\mathrm{TM}}$ cell lines expressing catalytic mutants of pol $\gamma-\alpha$ (D890N and D1135A, required for 5'-3' polymerase activity) and mtDNA helicase (K421A, implicated in ATP binding and hydrolysis; G575D, implicated in DNA binding; and a deletion of residues 70-343 that shows similarity with the T7 gp4 primase domain) showed mtDNA depletion, altered nucleoid localization, and replication stalling phenotypes. Notably, the stalling caused by pol $\gamma$ and mtDNA helicase mutants differs. The RIs observed in the mtDNA helicase stalling mutants were most likely doublestranded DNA (dsDNA) with loss of RITOLS, which the authors explain as an increased rate of lagging strand initiation and/ or RNA-DNA maturation relative to the rate of fork movement, consistent with the role of the mtDNA helicase in unwinding dsDNA. On the other hand, expression of pol $\gamma$ mutants induced replication stalling but maintained RITOLS and single-stranded RIs, primarily because of delayed lagging-strand DNA synthesis or its maturation. mtDNA replication stalling associated with impaired mtDNA helicase function has also recently been shown for human cell cultures expressing mtDNA helicase carrying autosomal dominant PEO (adPEO) mutations (Goffart et al. 2009). The RIs found in this study resemble those obtained with the expression of catalytic mutants of mtDNA helicase. 
In mice, the introduction of adPEO mutants of the mtDNA helicase, T360A and duplication of residues 353-365, partially recapitulated features of human patients (Tyynismaa et al. 2005). The T360A mutant only showed a mild phenotype, whereas mice over one year of age carrying the 353-365 deletion presented negative COX staining and enlarged mitochondria with concentric cristae in muscle fibers. Multiple mtDNA deletions were detected in the brain and curiously, a predominant $3-\mathrm{Kb}$ fragment of the mtDNA containing the $12 \mathrm{~S}$ and $16 \mathrm{~S}$ rRNA genes and the NCR was found in the muscles. mtDNA copy number did not appear to be affected in heart and muscles, but was clearly reduced in the brain to $40 \%$ when compared to control animals. Analysis of the mtDNA RIs of young mutant mice (6-weeks-old) showed accumulation of RIs indicative of replication stalling in the heart, muscle, kidney and brain, but not in the liver (Goffart et al. 2009). This difference may result from variations in tissue-specific expression of the mutant mtDNA helicase (e.g., transcript levels were $16 \%$ in the liver, and varied in other tissues from $13-59 \%$ as compared to endogenous levels of the wild-type enzyme), self-regenerating capacity, resistance to apoptosis, and/ or mode of replication.

Our group has studied the effects of active site and adPEO mutants of mtDNA helicase in Drosophila Schneider cells (Matsushima and Kaguni 2007, Matsushima and Kaguni 2009). The overexpression of the mtDNA helicase mutants K388A and D483A, analogous to $\mathrm{Lys}^{318}$ in the Walker A motif and Asp ${ }^{424}$ in the Walker B motif in the helicase domain of bacteriophage $\mathrm{T} 7 \mathrm{gp} 4$, respectively induced a severe dominant-negative phenotype resulting in lethality within 4-6 weeks. Furthermore, mtDNA copy number and transcription were reduced drastically to $4-10$ and $20 \%$ of control cells, respectively. Likewise, overexpression of Drosophila mtDNA helicase variants I334T and A442P that are located in the linker region and helicase domain, respectively, and are analogous to mutant alleles of human mtDNA helicase in adPEO patients (I367T and A475P), induced phenotypes as severe as the active site mutations. mtDNA copy number was reduced 7-11 fold, indicating conservation of structure/ function between the fly and human enzymes (Matsushima and Kaguni 2007). Mutations in the N-terminal domain are also associated with adPEO. We found that Drosophila Schneider cells overexpressing mtDNA helicase carrying W282L, R301Q, and P302L amino acid substitutions that are analogous to the W315L, R334Q, and P335L alleles found in human adPEO patients also showed reduced mtDNA copy number. Because we have failed to demonstrate a DNA primase activity in this region of the mitochondrial enzyme (Matsushima and Kaguni 2009) as found in T7 gp4, our current data argue that the $\mathrm{N}$-terminal region plays a role in the $\mathrm{C}$-terminal helicase function of the enzyme.

We have also evaluated the importance of the C-terminal region of the mtDNA helicase using a combination of in vitro and in vivo approaches (Matsushima et al 2008). Deletion and alanine substitution mutations revealed that residues $\mathrm{Lys}^{574}, \mathrm{Arg}^{576}, \mathrm{Tyr}^{577}, \mathrm{Ph}^{588}$ and $\mathrm{Tyr}^{595}$ of the fly protein are important for mtDNA maintenance and cell viability; overexpression of these mutants caused drastic mtDNA copy number reduction and lethality, again comparable to the Walker A and B active-site mutants. We produced recombinant forms of the human mtDNA helicase carrying the analogous mutations R609A, F621A, and F628A and found that these showed defects in DNA-dependent ATPase activity. Compared to the wild-type helicase, we observed 4- and 10- fold reduction in ATP hydrolysis for the F628A and F621A mutants, respectively. R609A showed no ATPase activity consistent with the role of this residue as the arginine finger in the human mtDNA helicase (Matsushima et al. 2008).

Disruption of pol $\gamma$ activity has also been the target of many studies employing Drosophila and mouse as models of mitochondrial biogenesis. In Drosophila melanogaster, pol $\gamma$ mutants with defects in the gene encoding the catalytic subunit, tamas, were isolated in a screen of pupal-lethal lines that showed a reduction in the larval response to light due to a 
primary deficit in locomotion (Iyengar et al. 1999). These mutants failed to undergo behavioral changes characteristic of the larval wandering stage: the foraging third instar larvae remained in the food substrate for a prolonged period and died at, or just before, pupariation. Mutant alleles resulted in truncated proteins via frame-shifting and an E814V amino acid substitution in the polymerase domain, and an E595A substitution in the linker region of the pol $\gamma$ catalytic core, concomitant with severe disruption of the pattern of mitochondrial distribution in the larval central nervous system. Several years later, Iyengar et al. (2002) described the first pol $\gamma$ accessory subunit mutants found in animals. A G31E amino acid substitution and a truncation caused by a $74 \mathrm{bp}$ insertion in the $\mathrm{N}$-terminal domain of pol $\gamma-\beta$ led to loss of mtDNA, disruption of mitochondrial morphology and impairment of cell proliferation in the larval brain, and consequent lethality at the early pupal stage. Recently, a mutation in the human pol $\gamma-\beta$ gene has been found in adPEO patients (review in Copeland 2008).

Our group has employed both the pol $\gamma-\alpha$ and $\beta$ mutants described above to study mitochondrial biogenesis and mitochondrial axonal transport when mtDNA replication is disrupted (Baqri et al. 2009). Here we found that mitochondrial density in the larval proximal nerves and muscles is increased $\sim 12 \%$ relative to control animals and surprisingly the flux of bidirectional mitochondrial transport along the axon was increased by nearly 2 fold. Mitochondrial biogenesis is believed to take place in the cell body, such that newly made healthy mitochondria are transported in the anterograde direction towards the axon terminal, whereas damaged, depolarized mitochondria show a retrograde transport towards the cell body for degradation or recycling (Miller and Sheetz 2004). Our data on disruption of mtDNA replication in Drosophila suggests that mitochondrial biogenesis and degradation are both increased, and that the elevated transport observed may represent a futile attempt to supply the axon with functional mitochondria. This study is particularly relevant to understand the roles of mitochondria in neurodegenerative diseases. In this regard we have reported that overexpression of Drosophila pol $\gamma$ - $\alpha$ in the nervous system reduces median life span of adult flies to 39-52\% of control animals, with only a moderate reduction in pupal eclosion (Martínez-Azorín et al. 2008). At the same time, OXPHOS activity and resistance to the ROS-generating agent paraquat were reduced by 70 and $40-50 \%$, respectively. Perhaps surprisingly, we found that mtDNA was depleted by $\sim 2$-fold, and in organello DNA synthesis indicated that mtDNA in these flies is synthesized at a much lower rate $(\sim 50 \%)$. Finally we observed that the level of apoptosis in the larval brain was increased by $\sim 30 \%$. In contrast with the phenotypes observed in adult flies in the nervous-system overexpression model, we showed in an earlier study that constitutive overexpression of pol $\gamma-\alpha$ in the whole animal is lethal at the pupal stage (Lefai et al. 2000). We observed that pupal mtDNA copy number and mitochondrial transcript levels in the constitutive overexpression model were reduced to $30-40 \%$ of those in control animals, suggesting that the excess of pol $\gamma$ - $\alpha$ might cause mtDNA replication stalling due to its 50 -fold reduced catalytic activity in the absence of comparable levels of pol $\gamma-\beta$, or alternatively as a result of its interaction with and sequestration of other mtDNA replication proteins, such as mtSSB. Interestingly, muscle-specific overexpression of pol $\gamma-\alpha$ produces nearly complete pupal lethality and a $60 \%$ reduction in life span of survivor adult flies, recapitulating the phenotype of constitutive overall overexpression and highlighting the potentially very different effects of altered levels of pol $\gamma-\alpha$ in relation to tissue-specific physiology (Martínez-Azorín et al., in preparation).

In a very recent study, Di Re et al. (2009) showed that knockdown of pol $\gamma-\beta$ in human 143B osteosarcoma cells caused mtDNA depletion (45\%), and increased the number of mitochondrial nucleoids after six days of treatment. In contrast, overexpression of the accessory subunit in HEK and U2OS cells did not affect mtDNA copy number, although the number of nucleoids was reduced and their size increased. These findings prompted the 
authors to suggest that pol $\gamma-\beta$ has an additional role other than in mtDNA synthesis per se, in regulating nucleoid structure via binding to the mtDNA D-loop region.

A "mtDNA mutator" mouse strain was obtained by replacement of pol $\gamma-\alpha$ gene with a proofreading-deficient catalytic core, which has a D257A substitution in the exonuclease domain of the enzyme (Edgar et al. 2009, Kujoth et al. 2005, Trifunovic et al. 2004, Vermulst et al. 2007, 2008). mtDNA mutation rate is increased in these mice as predicted, and longevity is reduced: the median life span is $\sim 48$ weeks and maximum age is 61 weeks. Signs of premature ageing were detected at 24-25 weeks of age, characterized by a loss of weight, kyphosis, alopecia, anemia, infertility, hearing loss and reduced hair density. Further analysis showed reduced subcutaneous fat content and whole-body bone mineral density and content. At an age of $\sim 40$ weeks, the mtDNA mutator mice showed an enlarged cardiac left ventricle cavity, COX deficiency and abnormal mitochondria. Both deletion and nucleotide substitution mutations were found in the mtDNA of these mice, although the nature of mutations that cause this complex phenotype remains a controversial topic. Vermulst et al. $(2007,2008)$ argue that deletions in mitochondrial protein-coding and/ or RNA genes are the driving force of such phenotypes, disagreeing with Edgar et al (2009) who claim that random nucleotide substitutions with major effects in protein-coding genes are causal. Linear mtDNA molecules of $\sim 11 \mathrm{~Kb}$ containing the genomic region between $\mathrm{O}_{\mathrm{H}}$ and $\mathrm{O}_{\mathrm{L}}$ have also been found, and evidence presented suggests that such molecules are produced as a result of enhanced replication pausing/ fragile sites (Bailey et al. 2009). Concern has been registered regarding the extrapolation of the conclusions drawn from the mouse data to human ageing, because the levels of mtDNA mutations in this model typically are more than an order of magnitude higher than those found in aged humans. For further discussion of the subject, we recommend the articles by Khrapko et al. (2006) and Kraytsberg et al. (2009).

Notwithstanding the number and type of mtDNA mutations associated with the ageing phenotype in this mouse model, the resultant defects may be expected to cause increased ROS production. However, ROS levels and mitochondrial oxidative stress were unchanged in the liver, and in cardiac and skeletal muscles of the mtDNA mutator mouse, failing to support a role for oxidative stress in the mitochondrial theory of ageing. Interestingly, widespread induction of apoptosis was detected in various mitotic and postmitotic tissues (Kujoth et al. 2005), suggesting that deregulation of programmed cell death may contribute to the profound ageing phenotype. Tissue dysfunction due to mtDNA mutations is likely to arise through apoptosis and subsequent loss of critical, irreplaceable cells. Remarkably, high levels of apoptosis were also observed in the fly model of pol $\gamma$ - $\alpha$ overexpression (as discussed above), the mouse model of RNase H1 knockout, the fly model of mtTFB2 knockdown, and various cell culture systems (as discussed below). Because mitochondrial dysfunction shows pronounced tissue-specific effects, it seems possible that although ROS are not increased in the organs that were analyzed (liver and striated muscles) in the mtDNA mutator mice, they may be increased in others that have not yet been examined. It remains possible that ROS are not involved in ageing whatsoever, but the pronounced phenotype of the mtDNA mutator mouse clearly shows the involvement of mtDNA mutations in this process. The roles of ROS and apoptosis in promoting ageing remain a fertile problem and in this regard, one concern in relating directly the findings observed in the mutator mouse with ageing is that the accumulation of mtDNA mutations in the mouse model takes place largely during embryogenesis. It will be important to generate animal models that express the mutator phenotype in postmitotic tissues, which represent the actual target of the ageing process.

In addition to pol $\gamma$ and the mtDNA helicase, the mitochondrial single-stranded DNAbinding protein, $\mathrm{mtSSB}$, also functions at the mtDNA replication fork. Our lab has demonstrated that Drosophila mtSSB can stimulate 15-20 fold both in vitro DNA synthesis 
and the 3'-5' exonuclease activity of Drosophila pol $\gamma$ (Farr et al. 1999, Thömmes et al. 1995). The human mtSSB has been shown to stimulate specifically the unwinding activity of the human mtDNA helicase (Korhonen et al. 2003) and together with pol $\gamma$ and mtDNA helicase, reconstitute a minimal mtDNA replisome in vitro (Korhonen et al. 2004). The biochemical data is consistent with an important role for mtSSB in initiation and elongation of DNA synthesis in mtDNA replication. This has been documented genetically by the observation that an insertion in the third intron of the Drosophila gene (lopo) results in developmental lethality in third instar larvae prior to metamorphosis (Maier et al. 2001). Molecular, histochemical and physiological experiments showed reduced cell proliferation in the central nervous system, with loss of mtDNA and concomitant loss of respiratory capacity. Interestingly, the number and morphology of mitochondria were not altered in the larval brain. Consistent with these results, the knockdown of mtSSB in Drosophila Schneider cells depletes mtDNA to $20 \%$ of the control level and results in growth defects (Farr et al. 2004). At the same time, overexpression of mtSSB restores cell growth and mtDNA copy number. However, the overexpression of a W79T/ F85A double mutant, a protein deficient both in ssDNA-binding and in stimulating pol $\gamma$ activity, neither rescues the cell growth defect nor the mtDNA depletion phenotype.

As discussed above, the extent of RNA molecules associated with mtDNA replication may vary according to the mode of replication operating. Notwithstanding this consideration, synthesis and processing of RNA primers represent essential steps in the replication process. Crouch and co-workers showed for the first time the link between RNase H1 and mtDNA maintenance when they knocked out the Rnasehl gene in mouse. Despite the dual nuclear

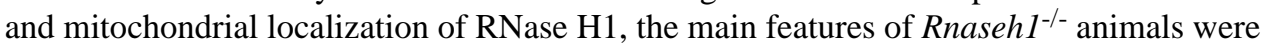
embryonic lethality concomitant with loss of mtDNA and COX activity, increased apoptosis and the presence of enlarged mitochondria with abnormal cristae (Cerritelli et al. 2003). Developmental arrest at the transition between the last larval instar and pupariation was also observed in Rnaseh1 ${ }^{-/}$flies (Filippov et al. 2001); although mtDNA maintenance was not analyzed directly, this phenotype is reminiscent with those already described in the various genetic and molecular genetic fly models of mtDNA transactions. The lethality caused by Rnasehl knockout is most likely due to the deficiency of RNase H1 either in generating RNA primers for lagging DNA strand synthesis from the long stretches of RNA associated with mtDNA, or in promoting the maturation of the RNA-containing RIs into fully-duplex progeny DNA molecules.

mtDNA replication, and the other mtDNA transactions reviewed here, create topological constraints on mtDNA and in particular, as a result of progression of replication forks and the transcriptional machinery. In addition, catenated DNA molecules likely arise from replication of supercoiled mtDNA (review in Zhang et al. 2007). The animal mitochondrion has three potential topoisomerases to deal with these topological problems: one type IA (Top $3 \alpha$ ), one type IB (Top $1 \mathrm{mt}$ ) and one type II (Top $2 \beta$ ). Top $2 \beta$ and Top $3 \alpha$ are primarily nuclear proteins that are targeted to the mitochondria via posttranscriptional mechanisms. Despite the lack of mtDNA analysis, animal models of Top $3 \alpha$ knockout in Drosophila and mouse were shown to cause developmental lethality due to nuclear DNA instability ( $\mathrm{Li}$ and Wang 1998, Plank et al. 2005). Top1mt, a paralog of the nuclear Top1, is found exclusively in the mitochondria of vertebrates and binds and cleaves mtDNA at three sites clustered within a 150 bp region downstream from the D-loop (Zhang and Pommier 2008, Figure 1). In a series of experiments, Dalla Rosa et al. (2009) explored the physiological differences between the mitochondrial and nuclear isoforms by targeting Top $1 \mathrm{mt}$ to the nucleus and Top1 to the mitochondria of human HT-1080 fibrosarcoma cells. In the first scenario, Top1mt failed to interact with metaphase chromosomes, yet no phenotypic alterations were observed. On the other hand, the targeting of Top1 to mitochondria promoted strong inhibition of mitochondrial transcription followed by a gradual decline in mtDNA content. 
The exact mechanism for this phenotype is not clear, but the data indicate clearly that in spite of the high sequence similarity between the two paralogs, they have adapted early in the evolution of vertebrates to the environment of their cellular compartments, which necessitates interactions with DNA in different conformations, and with their distinct replication and transcriptional machineries.

\section{Repair and recombination}

mtDNA is a prime target for oxidative damage for two key reasons. First, most cellular ROS are produced in mitochondria. Second, a variety of environmental toxins accumulate in mitochondria, and directly or indirectly modify the mtDNA (review in Bandy and Davidson 1990). Furthermore, antiviral therapeutic drugs, including HIV-1 reverse transcriptase inhibitors, affect mtDNA content and integrity via inhibition of the polymerase and exonuclease activities of pol $\gamma$ (reviewed in Kaguni 2004). One of the consequences of these susceptibilities is manifested in the high mutation rates reported in animal mtDNA as compared to the nuclear genome (Brown et al. 1979), despite the high nucleotide selectivity and exonucleolytic proofreading functions of pol $\gamma$ (reviewed in Kaguni 2004). Historically, it was thought that neither replicative nor post-replicative DNA repair mechanisms were present in mitochondria, and that excessively damaged mtDNA molecules would be degraded and replaced by newly synthesized molecules copied from undamaged mtDNAs (Druzhyna et al. 2008). It was not until the late 1980's that the 3'-5' exonuclease activity was identified in pol $\gamma$ with our work in Drosophila (Kaguni and Olson 1989), and that of others in vertebrates (Insdorf and Bogenhagen 1989, Kunkel and Soni 1988)). It is clear now that the integrity of the mitochondrial genome is also enforced by various post-replicational repair mechanisms, primarily base excision repair (BER) (Figure 3).

Mitochondrial single-nucleotide BER apparently proceeds by a mechanism similar to nuclear BER, in which a damaged or inappropriate base is recognized and removed by the action of DNA glycosylase, such as uracil DNA glycosylase (UDG), 8-oxoG DNA glycosylase/AP lyase (OGG1), MUTYH glycosylase, and thymine glycol glycosylase (NTH). Upon hydrolysis of the $\mathrm{N}$-glycosydic bond, the resulting 5'-deoxyribose phosphate is cleared by the lyase activity associated with these glycosylases or by that in pol $\gamma$ (Longley et al. 1998). Apurinic/ apyrimidinic endonuclease 1 can then cleave the 5' phosphodiester bond, creating a gap that can be filled by the actions of pol $\gamma$ and DNA ligase III (Figure 3, left). With the exception of pol $\gamma$, all of these enzymes have been found both in the nucleus and mitochondria of animal cells, either as a result of expression of both mitochondrial and nuclear isoforms, or by nucleus-to-mitochondria translocation (Englander et al. 2002, Lakshmipathy and Campbell 1999, Nishioka et al. 1999, Slupphaug et al. 1993, Tomkinson et al. 1988). When the expression of the human OGG1 protein was targeted to the mitochondria of HeLa cells in culture, their capacity to repair mtDNA oxidative damages that are induced by various agents was enhanced significantly, leading to an increase in cell survival under oxidative stress (Chatterjee et al. 2006). At the same time, when the R229Q mutant of the OGG1 protein that is found in human patients with leukemia was targeted to mitochondria, mtDNA integrity and survival of HeLa cells were reduced under oxidative stress, pointing to a link between defects in mtDNA repair and certain types of cancer.

Studies with cell lines derived from the central nervous system of mammals have indicated that the mtDNA repair system is regulated differently in neurons and glial cells.

Mitochondria from astrocytes can repair oxidative damage in mtDNA more efficiently than mitochondria from oligodendrocytes and microglia, with a positive correlation in oxidative damage-induced apoptosis (Hollensworth et al 2000, LeDoux et al. 1998). Targeting OGG1 to the mitochondria of oligodendrocytes promoted an increase in mtDNA repair and a 
decrease in caspase 9-dependent apoptosis after exposure of the cells to menadione (Druzhyna et al. 2003). Similar results were obtained when oligodendrocytes containing OGG1-enriched mitochondria were exposed to inflammatory cytokines, a process that increases cellular nitric oxide (NO) by inducing expression of NO synthase. NO accumulates in brains of human patients with multiple sclerosis (Druzhyna et al. 2005); it can damage mtDNA directly or indirectly and inhibit the activity of DNA repair enzymes (Jaiswal et al. 2001). The increase in mtDNA integrity and cell viability under oxidative stress was also observed when the yeast apurinic/ apyrimidinic endonuclease Apn1 was targeted to the mitochondria of a neuronal cell line derived from rat substantia nigra (Ho et al. 2007). Surprisingly, when the Drosophila OGG1 and RpS3 (ribosomal protein S3) glycosylases were targeted to the mitochondria of Schneider cells, they became more susceptible to hydrogen peroxide or paraquat treatment and apoptosis was increased relative to the control cells, despite the decrease of 1.4 to 6.7 fold in damaged mtDNA (Radyuk et al. 2006). The expression of such proteins in Drosophila mitochondria may actually cause a perturbation in the BER pathway, so the authors speculate that despite enhancement of the glycosylase and lyase activities, the capacity of pol $\gamma$ and DNA ligase III to complete the repair process is not increased, leading to the accumulation of nicked and/ or gapped mtDNA molecules and subsequent cell death. Interestingly however, Drosophila cells carrying OGG1- and RpS3-enriched mitochondria were more resistant to $S$-nitroso- $N$ acetylpenicillamine, an NO donor, probably due to alleviation of the glycosylase inhibition caused by NO (Jaiswal et al. 2001).

A second BER system that has been studied recently in mitochondria is the long-patch BER pathway. Fen1 and Dna2, familiar players in the processing of DNA intermediates during replication and repair in the nucleus, have been also identified in mitochondria. Fen1 is an endonuclease that binds and cleaves specifically flap DNA structures (Liu et al. 2004). Liu et al. (2008) have shown that 2-deoxyribonolactone (dL), present in mtDNA as a product of oxidative damage, blocks both the polymerase and exonuclease activities of pol $\gamma$, and that such a lesion is processed by a long-patch BER pathway dependent on Fen1 activity found in mitochondrial extracts of human GM1310 lymphoblasts. The knockdown of Fen1 in HeLa cells, without detectably compromising cell proliferation (Fen1 is also required for Okazaki fragments maturation during nuclear DNA replication), led to more pronounced oxidative damage in mtDNA immediately after $\mathrm{H}_{2} \mathrm{O}_{2}$ treatment, and the recovery of repaired mtDNA was delayed. Dna2 is a member of the nuclease/ helicase family whose nuclease activity is also dependent on a flap DNA structure. Unlike Fen1, Dna2 removes a portion of DNA in the middle of the ssDNA flap (Bae and Seo 2000). Interestingly, the comparison of the well-studied yeast protein with the human Dna2 indicated that the human protein, as well as other vertebrate Dna2s, lacks the nuclear localization sequence and the replication protein A binding domain (Zheng et al. 2008). In HeLa, fibroblast and melanoma H294T cells, human Dna2 was predominantly localized to mitochondria, and in vitro experiments showed that it interacts physically and functionally with pol $\gamma$ to promote DNA synthesis, and with Fen1 to perform efficient long-patch BER and RNA primer processing. In vivo Dna2 knockdown followed by $\mathrm{H}_{2} \mathrm{O}_{2}$ treatment revealed that mtDNA accumulates significantly more oxidative damage, and that the recovery from such stress is delayed. At the same time, nuclear genome does not suffer more damage in Dna2-depleted cells as compared to the control cells. In a similar study, Duxin et al. (2009) showed that in addition to the accumulation of mtDNA damage, the knockdown of Dna2 affects mtDNA replication quantitatively via a decrease in replication intermediates. Furthermore, the authors observed that Dna2 is important to maintain nuclear DNA stability, consistent with their localization of Dna2 in the nucleus of human BJ, HeLa, HEK293, U2OS, and 143B cells. Although function of Dna2 in the nucleus of mammalian cells warrants further investigation, it is clear that Dna2 plays an important role in mtDNA integrity. Thus it seems reasonable that Fen1 and Dna2, as well as the RNA/ DNA helicase Pif1, would function in maturation of the 
putative Okazaki fragments in semi-discontinuous mtDNA replication (reviewed in Holt 2009).

Large deletions in mtDNA are frequently associated with mitochondrial disorders and as such, constitute an important class of damaged DNA. Recently, in addition to models that suggest they are caused by errors in mtDNA replication, it was proposed that the generation of these deletions results from double-strand breaks (DSB) in mtDNA followed by DNA repair (Krishnan et al. 2008). Cellular repair mechanisms generally associated with DSB are homologous recombination (HR) or non-homologous end-joining (NHEJ). HR involves exchange of material between homologous segments (as short as $5 \mathrm{bp}$ in similarity) of damaged and undamaged DNA, whereas NHEJ involves the protection of DNA ends against nucleases by the joining of two unrelated segments. To our knowledge, no candidate enzymes, such as recombinases or junctional resolvases, have been identified in the mitochondrial proteome or isolated from animal mitochondria, but evidence for both mitochondrial HR and NHEJ processes have been reported (Bacman et al. 2009, D' Aurelio et al. 2004, Fukui and Moraes 2009, Kajander et al. 2001, Morel et al. 2008, Pohjoismäki et al. 2009, Srivastava and Moraes 2005, Tang et al. 2000, Thyagarajan et al. 1996, Zsurka et al. 2005). In Drosophila Schneider cells, a mitochondrial DSB repair mechanism was shown to be activated upon induction of DSBs with bleomycin (Morel et al. 2008): in a time-course experiment the authors showed that 50\% of mtDNA with DSB was repaired in 5 minutes after treatment with bleomycin; after 2 hours, nearly all molecules were repaired.

Moraes and coworkers have developed transgenic mice expressing mitochondrial-targeted bacterial endonucleases in order to study the effects of DSB in mtDNA. First, they expressed a mitochondrial-targeted PstI nuclease in mouse skeletal muscles (Srivastava and Moraes 2005). They showed induction of DSB in mtDNA such that transgenic founders developed a mitochondrial myopathy associated with mtDNA depletion. A specific set of $\sim 7$ $\mathrm{kb}$ mtDNA deletions was identified, predominantly involving one of the PstI sites and the 3 '-end of the D-loop region (adjacent to the tRNA ${ }^{\text {Pro }}$ and tRNA ${ }^{\text {Thr }}$ genes, see Figure 1), with either no or small direct repeats at the breakpoint regions. Notably, the breakpoints correspond to those observed in the multiple mtDNA deletions found in human muscles due to mitochondrial disease or ageing. Fukui and Moraes (2009) targeted the same restriction enzyme to the neuronal mitochondria of the brain cortex, hippocampus, and striatum of the mouse. When expressed constitutively, the enzyme caused limb-clasping, a well recognized neurological phenotype. In contrast, when the enzyme was expressed only during embryological development and the first three weeks of age, no apparent neurological problem was detected, but life span was shortened significantly. The mtDNA deletions that were generated and accumulated in these mouse brains differed in size, perhaps as a result of different mechanism of recombination. Finally, Bacman et al. (2009) introduced DSB into mtDNA by targeting ScaI to the mitochondria of heteroplasmic mice and HP202B cells in culture, taking advantage of the haplotype differences to trace the origin of the recombined molecules. Because ScaI has multiple recognition sites in the mouse mtDNA, the authors were able to identify hotspots of recombination, which primarily involved a region adjacent to the D-loop. In addition, inter-molecular recombination was observed, albeit at a very low frequency.

The final step in DNA replication, repair, and recombination processes in mitochondria is thought to require the action of DNA ligase III. Knockdown of DNA ligase III resulted in decreased mtDNA copy number and a $47-75 \%$ decrease in respiration in human fibrosarcoma-derived HT1080 cells (Lakshmipathy and Campbell 2001). Furthermore, the remaining mtDNA molecules contained numerous ssDNA breaks, suggesting that these cells are defective in sealing nicks generated during DNA replication and/ or repair. Exposure of DNA ligase III knockdown cells to $\gamma$-radiation showed that reduction in DNA ligase III 
diminished drastically the capacity of the cells to restore mtDNA copy number during a recovery period as compared to control cells, demonstrating the essential role of DNA ligase III in mtDNA maintenance.

There has been a recent increase in reports showing the participation of different types of proteins in the maintenance of mtDNA integrity through mechanisms that are not completely understood. Here, we will focus attention on two of these, p53 and parkin, because their association with mtDNA is relatively better understood. 30 years of study of the tumor suppressor p53 have shown that it functions as a global suppressor of inappropriate cell proliferation through induction of apoptosis, senescence or transient cellcycle arrest, and that mutations in its gene are present in a high proportion of human cancers, irrespective of their histological type (reviewed in Hainaut and Wiman 2009, and Vousden and Ryan 2009). Novel functions of p53, beyond its traditional role as guardian of the nuclear genome, are related to mitochondrial function in diverse ways. These include: regulation of expression of nuclear genes involved in glucose metabolism and mitochondrial respiration and in particular, in genes required for cytochrome $c$ oxidase assembly (Ma et al. 2007); the direct activation of Bax via translocation to mitochondria to mediate programmed cell death (Chipuk et al. 2004); physical association with mtDNA (Achanta et al. 2005, Heyne et al. 2004); and physical and functional interactions with pol $\gamma$, mitochondrial transcription factor A (TFAM) and mtSSB (Achanta et al. 2005, Wong et al. 2009a,b, Yoshida et al. 2003). Achanta et al. (2005) observed that different types of human $p 53^{-/-}$ cells in culture were extremely vulnerable to mtDNA depletion and respiratory deficiency after treatment with ethidium bromide (EtBr), a DNA intercalating agent known to affect preferentially mtDNA at low concentrations. In $p 53^{+/+}$cells, treatment with $\mathrm{EtBr}$ and rotenone, an inhibitor of complex I of mitochondrial OXPHOS and therefore a ROS generator, showed an enrichment of p53 in the mitochondria and its co-localization with pol $\gamma$, which implied that mtDNA damage is the primary signal for p53 translocation to mitochondria. Mitochondrial nucleoid remodeling is triggered by the presence of either $\mathrm{EtBr}$ or another DNA intercalating agent, doxorubicin, which is used in cancer therapy (Ashley and Poulton 2009). Treatment with doxorubicin of human fibroblasts in which p53 was knocked down or chemically inhibited resulted in fewer nucleoids of larger sizes, reminiscent of the results obtained with cells derived from the mtDNA mutator mouse. In another recent study, Lebedeva et al. (2009) showed that steady-state mtDNA copy number, mitochondrial membrane potential and mitochondrial mass are reduced 50,30, and $40 \%$, respectively, in $p 53^{-/-}$mouse neonatal fibroblasts, and in p53 knockdown in primary human fibroblasts in culture. In addition, TFAM and p53R2, the p53-regulated subunit of ribonucleotide reductase (mutations in this gene have been associated with mtDNA depletion syndromes; Bourdon et al. 2007), protein levels were significantly reduced, and cellular ROS homeostasis was disrupted, as reduced superoxide and increased $\mathrm{H}_{2} \mathrm{O}_{2}$ levels were observed. Taken together, these results are relevant to cancer research, especially involving the effects of mtDNA mutations in cancer progression.

Initially identified as an E3-ligase protein, parkin, a protein in which mutations are associated with the most common cases of autosomal recessive Parkinson's disease (PD) in humans (Park et al. 2009), has recently been found associated physically with mtDNA in the proliferating and differentiated human dopaminergic neuroblastoma cell line (SH-SY5Y), and in brain tissue of mouse and human origin (Rothfuss et al. 2009). Other genes causing PD, such as PINK1 and DJ-1 (Andres-Mateos et al. 2007, Pridgeon et al. 2007), are also linked to mitochondrial function, but have not yet been identified in association with mtDNA. Rothfuss et al. (2009) have shown that the overexpression of parkin in cell culture promotes increased mtDNA copy number and transcription, and protects mtDNA from oxidative stress-induced damage: a 50\% reduction in mtDNA lesions were observed in these cells compared to the control cells. In addition, mtDNA repair was increased $\sim 50 \%$ after 
$\mathrm{H}_{2} \mathrm{O}_{2}$ exposure followed by 2 hours of recovery. In human parkin-mutant fibroblasts, mtDNA copy number is reduced $\sim 20 \%$, and the genome is more susceptible to ROSinduced damage. Detailed experimentation on mouse (Goldberg et al. 2003, Palacino et al. 2004) and fly models (Greene et al., 2003; Pesah et al., 2004; Cha et al., 2005) has established a link between parkin and mitochondrial function. In particular, Drosophila has helped to establish the hypothesis that parkin is translocated inside the mitochondria via interactions with the mitochondrial-targeted serine/ threonine kinase PINK1. The parkinPINK1 pathway is likely involved in mitochondrial fusion and fission processes (Park et al. 2009 , and references therein), and the new findings that parkin is associated with mitochondrial nucleoids implies that it functions in proper nucleoid segregation during mitochondrial division (Rothfuss et al. 2009). However, how parkin protects mtDNA integrity is unclear and warrants further investigation.

\section{4. mtDNA transcription}

The core machinery for animal mitochondrial transcription (Figure 4) consists of a bacteriophage T-odd-related RNA polymerase (mtRNAP), the mitochondrial transcription factor A (TFAM) and two homologues of bacterial rRNA methyltransferases, the transcription factors B1 and B2 (mtTFB1 and mtTFB2, respectively). Among all mitochondrial nucleoid proteins, TFAM is the most abundant and well studied component (Garrido et al. 2003, Kanki et al. 2004, Kaufman et al. 2007, Larsson et al. 1998). Despite its involvement in in vitro reconstitution of the human mitochondrial transcription machinery (Falkenberg et al. 2002, Gaspari et al. 2004, McCulloch et al. 2002), the major role of TFAM is in mtDNA maintenance via packaging and compaction, similar to nuclear histones and the bacterial HU proteins (Alam et al. 2003, Kanki et al. 2004). We recommend the review by Wallace and Fan (2009) for a summary of mouse models of TFAM knockout.

Transcription in mammalian mtDNA originates from three regions located in the NCR: HSP1 and HSP2 are heavy strand promoters and LSP is the light strand promoter (Figure 1). Polycistronic transcripts comprising nearly the entire genome originate from HSP2 and LSP; they are then processed by the excision of tRNAs, which flank the majority of the proteincoding and rRNA genes, liberating the mRNAs and rRNAs. Transcription from HSP1 generates a transcript that comprises primarily the two rRNAs, permitting the mitochondria to produce more rRNA independent of mRNA production (reviewed in Bonawitz et al. 2006, Falkenberg et al. 2007).

In vivo studies with mtTFB1 and mtTFB2 were initiated in Drosophila Schneider cells and extended to human HeLa cell culture, transgenic flies and knockout mice (Adán et al. 2008, Cotney et al. 2007, Matsushima et al. 2004, Matsushima et al. 2005, Metodiev et al. 2009). We first knocked down mtTFB2 in Drosophila Schneider cells and evaluated the effects in mtDNA transcription and maintenance (Matsushima et al. 2004). mtTFB2 knockdown reduced cell growth, the abundance of $12 \mathrm{~S}$ rRNA, ND4, and Cytb transcripts $(57,16,13 \%$ of control cells, respectively), and mtDNA copy number (38\% of control). On the other hand, overexpression of mtTFB2 had no effect on cell growth or viability, but it promoted an $\sim 2$ fold increase in the mitochondrial transcripts and mtDNA copy number. The knockdown of mtTFB2 was also examined in transgenic flies constitutively expressing an inverted repeat fragment containing a Drosophila mtTFB2 cDNA (Adán et al. 2008). The transgenic animals died at the third larval instar stage, although this stage was dramatically prolonged (3-fold longer than in control larvae), and the larvae exhibited a 50\% decrease in mass. Further analysis showed that mtTFB2 knockdown had only a moderate effect on mtDNA copy number, but transcript levels were reduced by $50 \%$, concomitant with a decrease in OXPHOS activity and cell proliferation in larval brain, and an increase in apoptosis in wing imaginal discs. Interestingly, the long-lived larvae partially restored ATP 
synthesis by promoting a metabolic shift to glycolysis, and showed increased levels of mtTFB1 mRNA and protein (1.5-1.75 fold), suggesting a retrograde compensatory signaling in its nuclear gene expression. These results indicate that mtTFB2 is essential for mitochondrial transcription and animal development, and that it cannot be compensated by mtTFB1, despite their exchangeability in in vitro transcription assays (Falkenberg et al. 2002, McCulloch et al. 2002). A second retrograde signal affecting mtTFB1 levels was observed by Shadel and collaborators when they overexpressed mtTFB2 in human HeLa cells (Cotney et al. 2007). The authors observed a $\sim 2$ fold increase in mtTFB1 levels, concomitant with a 2 -fold increase in mitochondrial transcripts and mtDNA copy number that was consistent with results with mtTFB2 overexpression in Drosophila Schneider cells (Matsushima et al. 2004), and an increase in mitochondrial translation. In composite, the data in both models argue that mtTFB2 serves an important role in vivo in mitochondrial transcription and in transcription-primed mtDNA replication (discussed in Section 2).

The first in vivo evidence that mtTFB1 and mtTFB2 have clearly distinct function in mitochondria, despite their homology and equivalent in vitro functions as transcription activators (Falkenberg et al. 2002, McCulloch et al. 2002) and rRNA methyltransferases (Cotney and Shadel 2006), came from our studies of mtTFB1 in Schneider cells

(Matsushima et al. 2005). Here, the knockdown of mtTFB1 resulted in moderate cell growth retardation, with no change in the levels of mitochondrial transcripts or in mtDNA copy number. However, mtDNA-encoded proteins were reduced to $40 \%$ of those in control cells, suggesting a role for mtTFB1 in mitochondrial translation. Overexpression of mtTFB1 showed no significant effect on mtDNA copy number, mitochondrial transcription or translation. Again, similar findings were obtained upon overexpression of mtTFB1 in human HeLa cells (Cotney et al. 2007). Furthermore, the level of mtTFB2 was unchanged when mtTFB1 expression was altered in both Drosophila and human cells. Recently, Metodiev et al. (2009) showed that the knockout of mtTFB1 in mice result in embryonic lethality due to respiratory chain deficiency. Cardiac and skeletal muscle-specific $T \mathrm{fb} 1 \mathrm{~m}^{-/-}$mice had a shorter life span, and all of them died before 24 weeks of age, with increased heart weight, increased mitochondrial mass (> 50\%) and an increased number of mitochondria with abnormal cristae in cardiomyocytes, despite presenting a progressive deficiency in OXPHOS function. Consistent with the increase in mitochondrial mass, these knockout mice had elevated mtDNA copy number ( $\sim 50 \%)$, elevated TFAM ( 3.5 fold) and mtTFB 2 protein levels, and decreased MTERF3, a negative regulator of mammalian mtDNA transcription (discussed below). In combination, elevated TFAM and mtTFB2, and decreased MTERF3 likely promoted the 2.5 fold increase in de novo mitochondrial transcription. However, the steady-state levels of the 12S rRNA were dramatically reduced ( 40\% of control), along with a more dramatic reduction in mtDNA-encoded proteins ( 10\% of control). These results suggested that mtTFB1 participates directly in the stability of the 125 rRNA via its rRNA methyltransferase activity, and this hypothesis was confirmed when the authors verified that the $12 \mathrm{~S}$ rRNA of $T f b 1 m^{-/-}$mice lacked a dimethyl group in the conserved hairpin loop at the 3'-end of the molecule, which led to a specific loss of the small subunit of the mitochondrial ribosome. Altogether, the work in the Drosophila, human cell, and mouse models has demonstrated distinct and non-redundant roles of mtTFB1 and mtTFB2 in animal mitochondrial biogenesis: mtTFB1 has conserved its ancestral role in vivo as an rRNA methyltransferase and thus in protein translation, and mtTFB2 has evolved a role in promoting transcription of mitochondrial genes.

As important as are activation and initiation of transcription in mitochondria, is the regulation of these transactions via termination and/ or repression. Human mTERF, Drosophila DmTTF and the sea urchin mtDBP have all been shown to bind specific sequences in their respective genomes and promote transcription termination (reviewed in Roberti et al. 2009). In sea urchin, mtDBP is a strong transcriptional terminator, but it also 
controls the expansion of the small mtDNA D-loop via its counter-helicase activity, possibly coordinating the events of transcription and replication (Polosa et al. 2005, Roberti et al. 2009). In Drosophila, DmTTF binds two specific regions located at the end of blocks of mtDNA genes that are transcribed in opposite directions, and promotes transcription termination in vitro (Roberti et al. 2005). In vivo, DmTTF knockdown in Drosophila D.Mel-2 cells showed that the levels of transcripts from the mitochondrial genes located downstream from DmTTF binding sites (assuming that transcriptional initiation occurs in the mtDNA NCR in flies, also known as the A+T-rich region, Figure 1) was higher than in the control cells, and that the transcript levels of the genes located between the A+T-rich region and DmTTF binding sites were reduced (Roberti et al. 2009), suggesting a possible role in transcriptional activation similar to the human MTERF1 (discussed below). Although mtDNA copy number, and TFAM, mtTFB1 and mtTFB2 mRNA levels were not affected, changes in de novo mitochondrial protein synthesis correlated with changes in the mitochondrial mRNA levels. Overexpression of DmTTF decreased the transcript levels of genes mapping downstream of the DmTTF binding sites on both strands but surprisingly, de novo protein synthesis experiment showed either a reduction or no change in any of the mtDNA-encoded proteins. Thus, it is clear that the roles of DmTTF in regulating mitochondrial transcription and protein synthesis are complex, prompting future research.

The human mTERF protein, also known as MTERF1 (discussed below), is arguably the most important factor regulating the production of the transcript originating from the HSP1 promoter. It binds to a region at the 3'-end of the tRNA ${ }^{\text {Leu(UUR) }}$ gene and at the HSP1 region (Figure 1), which creates a loop between HSP1 and the end of the 16S rRNA gene, possibly facilitating reinitiation of transcription and enhancing production of the mitochondrial rRNAs, and therefore also functioning as a transcriptional activator (Fernandez-Silva et al. 1997, Martin et al. 2005). The binding of MTERF1 to HSP1 may also terminate transcription originated from the LSP promoter. Recently, a new role for MTERF1 in pausing of mtDNA replication has been proposed based on in vivo studies with human HEK293T, 143B osteosarcoma, Jurkat and HeLa cells, in cell culture and organ samples (Hyvärinen et al. 2007). First, the authors identified new MTERF1 binding sites throughout the mtDNA in addition to the canonical site in the tRNA ${ }^{\text {Leu(UUR) }}$ gene, by overexpressing the protein in cell culture and performing electrophoretic mobility shift assays and mtDNA immunoprecipitation. Interestingly, they observed that these new binding sites coincided relatively well with sites of mtDNA replication pausing, as analyzed by 2DAGE. However, replication pausing was not observed at all sites concomitantly; there was a great variability that depended on the cell type or organ tissue analyzed.

Overexpression of MTERF1 in general enhanced the RIs representing replication pausing, and it appeared that the level of 7S DNA, which is part of the triple-stranded D-loop region, was increased. The knockdown of the protein had an opposite effect: pause sites were substantially decreased, especially in the region containing its canonical binding site. Like the sea urchin mtDBP, human MTERF1 may coordinate the passage of the mitochondrial replication and transcription machineries, safeguarding the integrity of the mtDNA and facilitating efficient gene expression.

Recent bioinformatic and phylogenetic analyses have identified three additional paralogs of the human MTERF1 in the nuclear genome, named MTERF2 to MTERF4 (Linder et al. 2005). The biochemical and physiological roles of these proteins have just very recently been addressed in animals. MTERF3 was the first shown to have mitochondrial localization and an important mitochondrial function (Park et al. 2007, Roberti et al. 2006, Roberti et al. 2009). In Drosophila D.Mel-2 cells, the overexpression of MTERF3 promoted a decrease of 0.2-0.6 fold in the steady-state levels of the 12S rRNA, COI, and ND2 transcripts (Roberti et al. 2009). mtDNA copy number and the levels of TFAM, mtTFB1 and mtTFB2 mRNA were not affected, indicating a role of MTERF3 as a negative regulator of mitochondrial 
transcription. In contrast, MTERF3 knockdown had no effect on the levels of mitochondrial transcripts, but de novo synthesis of mtDNA-encoded proteins decreased overall (Roberti et al. 2006). Furthermore, analysis of TFAM, mtTFB1 and mtTFB2 mRNA levels showed that TFAM and mtTFB1 were depleted in MTERF3 knockdown cells (Roberti et al. 2009). The authors explained the unaltered levels of mitochondrial transcripts as a counterbalanced effect of depleting the negative regulator MTERF3 and the activator TFAM at the same time. The reduction of mtDNA-encoded proteins was likely due to mtTFB1 depletion. In the mouse, Park et al. (2007) showed that the knockout of MTERF3 resulted in embryonic lethality due to respiratory chain deficiency, similar to the results in $T \mathrm{fb} 1 \mathrm{~m}^{-/-}$mice. Specific disruption of MTERF3 in the heart and skeletal muscle shortened life span to a maximum of 18 weeks, due to a progressive deterioration of the activity and assembly of OXPHOS complexes I, III-V. The mice exhibited increased heart weight, increased mitochondrial mass (143-192\%) and an increased number of abnormal mitochondria in cardiomyocytes. mtDNA copy number was unchanged as compared to the control mice, but mitochondrial transcripts were generally elevated, especially the HSP transcripts. mtDNA immunoprecipitation revealed that MTERF3 binds to a region containing the HSP promoters, indicating that it regulates transcription at the level of initiation.

To our knowledge, no physiological studies have been reported to date on MTERF4. On the other hand, Wenz et al. (2009) have reported on MTERF2 function and its possible interactions with MTERF1 and MTERF3 in regulating mtDNA transcription. Unlike MTERF3, the constitutive knockout of MTERF2 in the mouse was not lethal; the knockout animals had no alterations in life span, basal metabolism or heat production, despite a slight decrease in body weight. However, Mterf $2^{-/-}$mice showed defects in OXPHOS function due to decreased steady-state levels of the individual OXPHOS complexes primarily in skeletal muscle, leading to mitochondrial myopathy. When the knockout mice were metabolically challenged with a ketogenic-rich diet that forces the animals to produce ATP via fatty acid oxidation and mitochondrial OXPHOS, the myopathy phenotype was enhanced, memory deficits observed, and OXPHOS defects were found in different tissues. As frequently observed for deficiencies in OXPHOS, knockout of MTERF2 triggered compensatory responses to promote mitochondrial biogenesis, including increased mtDNA copy number, but these mitochondria were enlarged with abnormal morphology. Interestingly, none of these effects were observed in the mouse heart, indicating tissue-specific regulation of MTERF2. Finally, the authors showed that the decrease in OXPHOS proteins were due to a decrease in the steady-state levels of mitochondrial mRNAs and imbalanced tRNA levels, suggesting that MTERF2 is a positive regulator of transcription, opposite to MTERF3. Electrophoretic mobility shift analysis, mtDNA immunoprecipitation and protein coimmunoprecipitation showed that MTERF1, MTERF2, and MTERF3 bind specifically to the HSP promoter region, and may coordinate initiation of mitochondrial transcription, possibly influencing the assembly of the transcriptional machinery. Thus, although a complete understanding of the regulation of mitochondrial transcription remains elusive, these new findings advance the field and document its clearly complexity.

\section{Concluding remarks and perspectives}

Mitochondrial research has advanced at a fascinating pace, such that this review, covering the current status of mtDNA transactions as an important part of the mitochondrial biogenesis process, will likely be out-of-date in a matter of few years. We expect here to have given an extended summary of the scientific progress that the field has observed, especially for the last decade, by discussing the contributions from the work of ours and others in different animal models. It is clear to the authors that the processes involved in mtDNA transactions play a central role in the biology and medicine of mitochondria and therefore, in the life of eukaryotic organisms. Human ageing and diseases including adPEO, 
PD and numerous others can be modeled by deregulating many of the mtDNA transaction processes. At the same time, the increase in ROS as a result of this deregulation is not completely clear. The DNA repair mechanisms in mitochondria, now shown to be diverse and relatively efficient, clearly protect mtDNA from ROS-induced damage. p53 knockout/ knockdown, for example, produces ROS imbalance and decreases mtDNA integrity and copy number. However, ROS levels are apparently not changed in the cells of the mtDNA mutator mouse, despite the constant increase in mtDNA mutations throughout the life span. For a detailed discussion of ROS production and mitochondrial function, we suggest the articles by Druzhyna et al. (2008), Jang and Van Remmen (2009), Thompson (2006), and Wallace and Fan (2009).

As we reviewed here, mutations in and/ or deregulation of expression of the well-known proteins involved in mtDNA organization, replication and transcription (pol $\gamma, \mathrm{mtDNA}$ helicase, mtSSB, mtTFB2 and MTERF1) promote mitochondrial dysfunction with different outcomes: null mutations of pol $\gamma-\alpha$, pol $\gamma-\beta$ and mtSSB in Drosophila result in lethality; overexpression/ knockdown of MTERF1 in cell culture demonstrate that regulation of mtDNA replication and transcription are tightly linked; overexpression of pol $\gamma$ and mtDNA helicase mutants in cell culture promotes distinct aberrations in mtDNA replication; expression of an adPEO mutant of mtDNA helicase in mouse causes an adPEO-like phenotype; expression of a proofreading-deficient mutation of pol $\gamma$ - $\alpha$ created the mtDNA mutator mouse and caused premature ageing with reduced life span; constitutive and neuron-specific overexpression of pol $\gamma-\alpha$ in Drosophila causes lethality and reduced life span, respectively; and knockdown of mtTFB2 caused lethality in Drosophila. In many of these cases, increased compensatory mitochondrial biogenesis is stimulated in the cells, despite the lack of success to restore ATP production via OXPHOS. Notably, where apoptotic markers were examined, higher levels of mitochondrial dysfunction-induced apoptosis were observed, indicating a conserved mechanism of elimination of cells containing damaged mitochondria and a possible role for this process in ageing, and suggesting a rich area for future research.

Regarding mitochondrial transcription, former issues have been resolved and new regulators identified. In vivo studies have shown that $\mathrm{mtTFB} 1$ and $\mathrm{mtTFB} 2$ are not redundant proteins: mtTFB1 methylates 12S rRNA and, is required for translation of mtDNA-encoded proteins, whereas mtTFB2 regulates mitochondrial transcription and transcription-mediated mtDNA replication, and is necessary for animal development. MTERF3 has been shown to be required for mouse development due to its ability to down-regulate mitochondrial transcription. MTERF2, on the other hand, appears to up-regulate transcription, but it is not absolutely required for development. Further investigations of the regulation of mitochondrial transcription through the interactions of transcription factors, terminators and mtDNA are warranted to expand our understanding of this apparently complex system.

With regard to current models of mtDNA replication, substantial future experimentation is needed to identify new protein players such as a primase, helicase loader and/ or an initiator, for full reconstitution of the mtDNA replisome in vitro, and to examine comprehensively multiple animal models through the application of approaches such as 2DAGE and electron microscopy. This will allow us to address the potentially multifarious responses of a particular cell type to ensure appropriate mtDNA copy number and mitochondrial gene expression. We might envision that different cell types would be able to switch among various mtDNA replication modes, and/ or that specific replication modes may be related to specific types of mtDNA organization comprising dynamic mtDNA: protein complexes. This latter possibility has recently been evidenced in human heart and brain, and mouse heart mtDNA (Pohjoismäki et al. 2009), and represents a new avenue for understanding tissue variability in mitochondrial diseases. 


\section{Acknowledgments}

LSK wishes to dedicate this review to Dr. Robert Lehman on the occasion of his $85^{\text {th }}$ birthday, with gratitude for his more than $50 \mathrm{yrs}$ as a model of outstanding science, family and mentoring. We would like to thank Rosângela A. Rodrigues and Dr. Ana C. Lessinger for assistance with Figure 1. This work was supported by the National Institutes of Health (grant GM45295 to LSK) and the Instituto de Salud Carlos III (grant PI070167 to RG).

\section{References}

Achanta G, Sasaki R, Feng L, Carew JS, Lu W, Pelicano H, Keating MJ, Huang P. Novel role of p53 in maintaining mitochondrial genetic stability through interaction with DNA pol gamma. EMBO J. 2005; 24:3482-3492. [PubMed: 16163384]

Adán C, Matsushima Y, Hernández-Sierra R, Marco-Ferreres R, Fernández-Moreno MA, GonzálezVioque E, Calleja M, Aragón JJ, Kaguni LS, Garesse R. Mitochondrial transcription factor B2 is essential for metabolic function in Drosophila melanogaster development. J Biol Chem. 2008; 283:12333-12342. [PubMed: 18308726]

Alam TI, Kanki T, Muta T, Ukaji K, Abe Y, Nakayama H, Takio K, Hamasaki N, Kang D. Human mitochondrial DNA is packaged with TFAM. Nucleid Acids Res. 2003; 31:1640-1645.

Andres-Mateos E, Perier C, Zhang L, Blanchard-Fillion B, Greco TM, Thomas B, Ko HS, Sasaki M, Ischiropoulos H, Przedborski S, Dawson TM, Dawson VL. DJ-1 gene deletion reveals that DJ-1 is an atypical peroxiredoxin-like peroxidase. Proc Natl Acad Sci USA. 2007; 104:14807-14812. [PubMed: 17766438]

Ashley N, Poulton J. Anticancer DNA intercalators cause p53-dependent mitochondrial DNA nucleoid re-modelling. Oncogene. 2009; 28:3880-3891. [PubMed: 19684617]

Bacman SR, Williams SL, Moraes CT. Intra- and inter-molecular recombination of mitochondrial DNA after in vivo induction of multiple double-strand breaks. Nucleic Acids Res. 2009; 37:42184226. [PubMed: 19435881]

Bae SH, Seo YS. Characterization of the enzymatic properties of the yeast dna2 helicase/ endonuclease suggests a new model for Okazaki fragment processing. J Biol Chem. 2000; 277:26632-26641. [PubMed: 12004053]

Bandy B, Davidson AJ. Mitochondrial mutations may increase oxidative stress: implication for carcinogenesis and ageing? Free Radical Biol Med. 1990; 8:523-539. [PubMed: 2193852]

Baqri RM, Turner BA, Rheuben MB, Hammond BD, Kaguni LS, Miller KE. Disruption of mitochondrial DNA replication in Drosophila increases mitochondrial fast axonal transport in vivo. PLoS ONE. 2009; 4:e7874. [PubMed: 19924234]

Bailey LJ, Cluett TJ, Reyes A, Prolla TA, Poulton J, Leeuwenburgh C, Holt IJ. Mice expressing an error-prone DNA polymerase in mitochondria display elevated replication pausing and chromosomal breakage at fragile sites of mitochondrial DNA. Nucleic Acids Res. 2009; 37:23272335. [PubMed: 19244310]

Bogenhagen DF. Does mtDNA nucleoid organization impact aging? Exp Gerontol. 200910.1016/ j.exger.2009.12.002

Bogenhagen DF, Clayton DA. The mitochondrial DNA replication bubble has not burst. Trends Biochem Sci. 2003a; 28:357-360. [PubMed: 12878002]

Bogenhagen DF, Clayton DA. Concluding remarks: The mitochondrial DNA replication bubble has not burst. Trends Biochem Sci. 2003b; 28:404-405. [PubMed: 12932727]

Bonawitz ND, Clayton DA, Shadel GS. Initiation and beyond: multiple functions of the human mitochondrial transcription machinery. Mol Cell. 2006; 24:813-825. [PubMed: 17189185]

Boore JL. Animal mitochondrial genomes. Nucleic Acids Res. 1999; 27:1767-1780. [PubMed: 10101183]

Bourdon A, Minai L, Serre V, Jais JP, Sarzi E, Aubert S, Chretien D, de Lonlay P, Paquis-Flucklinger V, Arakawa H, Nakamura Y, Munnich A, Rotig A. Mutation of RRM2B, encoding p53-controlled ribonucleotide reductase (p53R2), causes severe mitochondrial DNA depletion. Nat Genet. 2007; 39:776-780. [PubMed: 17486094]

Brown WM, George M, Wilson AC. Rapid evolution of animal mitochondrial DNA. Proc Natl Acad Sci USA. 1979; 76:1967-1971. [PubMed: 109836] 
Cha GH, Kim S, Park J, Lee E, Kim M, Lee SB, Kim JM, Chung J, Cho KS. Parkin negatively regulates JNK pathway in the dopaminergic neurons of Drosophila. Proc Natl Acad Sci USA. 2005; 102:10345-10350. [PubMed: 16002472]

Chatterjee A, Mambo E, Zhang Y, DeWeese T, Sidransky D. Targeting of mutant hOGG1 in mammalian mitochondria and nucleus: effect on cellular survival upon oxidative stress. BMC Cancer. 2006; 6:235. [PubMed: 17018150]

Chipuk JE, Kuwana T, Bouchier-Hayes L, Droin NM, Newmeyer DD, Schuler M, Green DR. Direct activation of Bax by 553 mediates mitochondrial membrane permeabilization and apoptosis. Science. 2004; 303:1010-1014. [PubMed: 14963330]

Clayton DA. Replication of animal mitochondrial DNA. Cell. 1982; 28:693-705. [PubMed: 6178513]

Copeland WC. Inherited mitochondrial diseases of DNA replication. Annu Rev Med. 2008; 59:131146. [PubMed: 17892433]

Cotney JL, Shadel GS. Evidence for an early gene duplication event in the evolution of the mitochondrial transcription factor B family and maintenance of rRNA methyltransferase activity in human mtTFB1 and mtTFB2. J Mol Evol. 2006; 63:707-717. [PubMed: 17031457]

Cotney JL, Wang Z, Shadel GS. Relative abundance of the human mitochondrial transcription system and distinct roles for h-mtTFB1 and h-mtTFB2 in mitochondrial biogenesis and gene expression. Nucleic Acids Res. 2007; 35:4042-4054. [PubMed: 17557812]

D’Aurelio M, Gajewski CD, Lin MT, Mauck WM, Shao LZ, Lenaz G, Moraes CT, Manfredi G. Heterologous mitochondrial DNA recombination in human cells. Hum Mol Genet. 2004; 13:31713179. [PubMed: 15496432]

Di Re M, Sembongi H, He J, Reyes A, Yasukawa T, Martinsson P, Bailey LJ, Goffart S, Boyd-Kirkup JD, Wong TS, Fersht AR, Spelbrink JN, Holt IJ. The accessory subunit of mitochondrial DNA polymerase $\gamma$ determines the DNA content of mitochondrial nucleoids in human cultured cells. Nucleic Acids Res. 200910.1093/nar/gkp614

Druzhyna NM, Hollensworth SB, Kelley MR, Wilson GL, LeDoux SP. Targeting human 8oxoguanine glycosylase to mitochondria of oligodendrocytes protects against menadione-induced oxidative stress. Glia. 2003; 42:370-378. [PubMed: 12730957]

Druzhyna NM, Musiyenko SI, Wilson GL, LeDoux SP. Cytokines induce NO-mediated mtDNA damage and apoptosis in oligodendrocytes. Protective role of targeting 8-oxoguanine glycosylase to mitochondria. J Biol Chem. 2005; 280:21673-21679. [PubMed: 15811855]

Druzhyna NM, Wilson GL, LeDoux SP. Mitochondrial DNA repair in ageing and disease. Mech Ageing Dev. 2008; 129:383-390. [PubMed: 18417187]

Duxin JP, Dao B, Martinsson P, Rajala N, Guittat L, Campbell JL, Spelbrink JN, Stewart SA. Human Dna2 is a nuclear and mitochondrial DNA maintenance protein. Mol Cell Biol. 2009; 29:42744282. [PubMed: 19487465]

Edgar D, Shabalina I, Camara Y, Wredenberg A, Calvaruso MA, Nijtmans L, Nedergaard J, Cannon B, Larsson NG, Trifunovic A. Random point mutations with major effects on protein-coding genes are the driving force behind premature ageing in mtDNA mutator mice. Cell Metab. 2009; 10:131138. [PubMed: 19656491]

Englander EW, Hu Z, Sharma A, Lee HM, Wu ZH, Greeley GH. Rat MYH, a glycosylase for repair of oxidatively damaged DNA, has brain-specific isoforms that localize to neuronal mitochondria. J Neurochem. 2002; 83:1471-1480. [PubMed: 12472901]

Falkenger M, Gaspari M, Rantanen A, Trifunovic A, Larsson NG, Gustafsson CM. Mitochondrial transcription factors B1 and B2 activate transcription of human mtDNA. Nat Genet. 2002; 31:289294. [PubMed: 12068295]

Falkenberg M, Larsson NG, Gustafsson CM. DNA replication and transcription in mammalian mitochondria. Annu Rev Biochem. 2007; 76:679-699. [PubMed: 17408359]

Farr CL, Matsushima Y, Lagina AT III, Luo N, Kaguni LS. Physiological and biochemical defects in functional interactions of mitochondrial DNA polymerase and DNA-binding mutants of singlestranded DNA-binding protein. J Biol Chem. 2004; 279:17047-17053. [PubMed: 14754882]

Farr CL, Wang Y, Kaguni LS. Functional interactions of mitochondrial DNA polymerase and singlestranded DNA-binding protein: template-primer DNA binding and initiation and elongation of DNA strand synthesis. J Biol Chem. 1999; 274:14779-14785. [PubMed: 10329675] 
Fernandez-Silva P, Martinez-Azorin F, Micol V, Attardi G. The human mitochondrial transcription termination factor (mTERF) is a multizipper protein but binds to DNA as a monomer, with evidence pointing to intramolecular leucine zipper interactions. EMBO J. 1997; 16:1066-1079. [PubMed: 9118945]

Fukui H, Moraes CT. Mechanisms of formation and accumulation of mitochondrial DNA deletions in ageing neurons. Hum Mol Gen. 2009; 18:1028-1036. [PubMed: 19095717]

Garrido N, Griparic L, Jokitalo E, Wartiovaara J, van der Bliek AM, Spelbrink JN. Composition and dynamics of human mitochondrial nucleoids. Mol Biol Cell. 2003; 14:1583-1596. [PubMed: 12686611]

Gaspari M, Falkenberg M, Larsson NG, Gustafsson CM. The mitochondrial RNA polymerase contributes critically to promoter specificity in mammalian cells. EMBO J. 2004; 23:4606-4614. [PubMed: 15526033]

Goddard JM, Wolstenholme DR. Origin and direction of replication in mitochondrial DNA molecules from genus Drosophila. Nucleic Acids Res. 1980; 8:741-757. [PubMed: 6253922]

Goffart S, Cooper HM, Tyynismaa H, Wanrooij S, Suomalainen A, Spelbrink JN. Twinkle mutations associated with autosomal dominant progressive external ophthalmoplegia lead to impaired helicase function and in vivo mtDNA replication stalling. Hum Mol Genet. 2009; 18:328-340. [PubMed: 18971204]

Goldberg MS, Fleming SM, Palacino JJ, Cepeda C, Lam HA, Bhatnagar A, Meloni EG, Wu N, Ackerson LC, Klapstein GJ, Gajendiran M, Roth BL, Chesselet MF, Maidment NT, Levine MS, Shen J. Parkin-deficient mice exhibit nigrostriatal deficits but not loss of dopaminergic neurons. J Biol Chem. 2003; 278:43628-43635. [PubMed: 12930822]

Greene JC, Whitworth AJ, Kuo I, Andrews LA, Feany MB, Pallanck LJ. Mitochondrial pathology and apoptotic muscle degeneration in Drosophila parkin mutants. Proc Natl Acad Sci USA. 2003; 100:4078-4083. [PubMed: 12642658]

Hainaut P, Wiman KG. 30 years and a long way into p53 research. Lancet Oncol. 2009; 10:913-919. [PubMed: 19717093]

Harman D. The biologic clock: the mitochondria? J Am Geriatr Soc. 1972; 20:145-147. [PubMed: 5016631]

Heyne K, Mannebach S, Wuertz E, Knaup KX, Mahyar-Roemer M, Roemer K. Identification of a putative p53 binding sequence within the human mitochondrial genome. FEBS Lett. 2004; 578:198-202. [PubMed: 15581641]

Ho R, Rachek LI, Xu Y, Kelley MR, LeDoux SP, Wilson GL. Yeast apurinic/ apyrimidinic endonuclease Apn1 protects mammalian neuronal cell line from oxidative stress. J Neurochem. 2007; 102:13-24. [PubMed: 17506861]

Hollensworth BS, Shen C, Sim JE, Spitz DR, Wilson GL, LeDoux SP. Glial cell type-specific responses to menadione-induced oxidative stress. Free Radical Biol Med. 2000; 28:1161-1174. [PubMed: 10889445]

Holt IJ. Mitochondrial DNA replication and repair: all a flap. Trends Biochem Sci. 2009; 34:358-365. [PubMed: 19559620]

Holt IJ, Jacobs HT. Response: The mitochondrial DNA replication bubble has not burst. Trends Biochem Sci. 2003; 28:355-356. [PubMed: 12878001]

Holt IJ, Lorimer HE, Jacobs HT. Coupled leading- and lagging-strand synthesis of mammalian mitochondrial DNA. Cell. 2000; 100:515-524. [PubMed: 10721989]

Hyvärinen AK, Pohjoismäki JLO, Reyes A, Wanrooij S, Yasukawa T, Karhunen PJ, Spelbrink JN, Holt IJ, Jacobs HT. The mitochondrial transcription terminator factor mTERF modulates replication pausing in human mitochondrial DNA. Nucleic Acids Res. 2007; 35:6458-6474. [PubMed: 17884915]

Insdorf NF, Bogenhagen DF. DNA polymerase gamma from Xenopus laevis. I. The identification of a high molecular weight catalytic subunit by a novel DNA polymerase photolabeling procedure. $\mathrm{J}$ Biol Chem. 1989; 264:21491-21497. [PubMed: 2600077]

Iyengar B, Luo N, Farr CL, Kaguni LS, Campos AR. The accessory subunit of DNA polymerase $\gamma$ is essential for mitochondrial DNA maintenance and development in Drosophila melanogaster. Proc Natl Acad Sci USA. 2002; 99:4483-4488. [PubMed: 11917141] 
Iyengar B, Roote J, Campos AR. The tamas gene, identified as a mutation that disrupts larval behavior in Drosophila melanogaster, codes for the mitochondrial DNA polymerase catalytic subunit (DNApol- $\gamma 125)$. Genetics. 1999; 153:1809-1824. [PubMed: 10581287]

Jaiswal M, LaRusso NF, Nishioka N, Nakabeppu Y, Gores GJ. Human Ogg1, a protein involved in the repair of 8-oxoguanine, in inhibited by nitric oxide. Cancer Res. 2001; 61:6388-6393. [PubMed: 11522631]

Jang YC, Van Remmen H. The mitochondrial theory of ageing: insights from transgenic and knockout mouse models. Exp Gerontol. 2009; 44:256-260. [PubMed: 19171187]

Kaguni LS. DNA polymerase $\gamma$, the mitochondrial replicase. Annu Rev Biochem. 2004; 73:293-320. [PubMed: 15189144]

Kaguni LS, Olson MW. Mismatch-specific 3'----5' exonuclease associated with the mitochondrial DNA polymerase from Drosophila embryos. Proc Natl Acad Sci USA. 1989; 86:6469-6473. [PubMed: 2671990]

Kajander OA, Karhunen PJ, Holt IJ, Jacobs HT. Prominent mitochondrial DNA recombination intermediates in human heart muscle. EMBO Rep. 2001; 2:1007-1012. [PubMed: 11713192]

Kanki T, Nakayama H, Sasaki N, Takio K, Alam TI, Hamasaki N, Kang D. Mitochondrial nucleoid and transcription factor A. Ann NY Acad Sci. 2004; 1011:61-68. [PubMed: 15126284]

Kaufman BA, Durisic N, Mativetsky JM, Costantino S, Hancock MA, Grutter P, Shoubridge EA. The mitochondrial transcription factor TFAM coordinates the assembly of multiple DNA molecules into nucleoid-like structures. Mol Biol Cell. 2007; 18:3225-3236. [PubMed: 17581862]

Khrapko K, Kraytsberg Y, de Grey ADNJ, Schon EA. Does premature aging of the mtDNA mutator mouse prove that mtDNA mutations are involved in natural aging? Aging Cell. 2006; 5:279-282. [PubMed: 16842501]

Korhonen JA, Gaspari M, Falkenberg M. TWINKLE has 5' $\rightarrow$ ' ' DNA helicase activity and is specifically stimulated by mitochondrial single-stranded DNA-binding protein. J Biol Chem. 2003; 278:48627-48632. [PubMed: 12975372]

Korhonen JA, Pham XH, Pellegrini M, Falkenberg M. Reconstitution of a minimal mtDNA replisome in vitro. EMBO J. 2004; 23:2423-2429. [PubMed: 15167897]

Kraytsberg Y, Simon DK, Turnbull DM, Khrapko K. Do mtDNA deletions drive premature aging in mtDNA mutator mice? Aging Cell. 2009; 8:502-506. [PubMed: 19416127]

Krishnan KJ, Reeve AK, Samuels DC, Chinnery PF, Blckwood JK, Taylor RW, Wanrooij S, Spelbrink JN, Lightowlers RN, Turnbull DM. What causes mitochondrial DNA deletions in human cells? Nat Genet. 2008; 40:275-279. [PubMed: 18305478]

Kujoth GC, Hiona A, Pugh TD, Someya S, Panzer K, Wohlgemuth SE, Hofer T, Seo AY, Sullivan R, Jobling WA, Morrow JD, Van Remmen H, Sedivy JM, Yamasoba T, Tanokura M, Weindruch R, Leeuwenburgh C, Prolla TA. Mitochondrial DNA mutations, oxidative stress, and apoptosis in mammalian ageing. Science. 2005; 309:481-484. [PubMed: 16020738]

Kunkel TA, Soni A. Exonucleolytic proofreading enhances the fidelity of DNA synthesis by chick embryo DNA polymerase-gamma. J Biol Chem. 1988; 263:4450-4459. [PubMed: 2831231]

Lakshmipathy U, Campbell C. The human DNA ligase III gene encodes nuclear and mitochondrial proteins. Mol Cell Biol. 1999; 19:3869-3876. [PubMed: 10207110]

Lakshmipathy U, Campbell C. Antisense-mediated decrease in DNA ligase III expression results in reduced mitochondrial DNA integrity. Nucleic Acids Res. 2001; 29:668-676. [PubMed: 11160888]

Larsson NG, Wang J, Wilhelmsson H, Oldfors A, Rustin P, Lewandoski M, Barsh GS, Clayton DA. Mitochondrial transcription factor A is necessary for mtDNA maintenance and embryogenesis in mice. Nat Genet. 1998; 18:231-236. [PubMed: 9500544]

Lebedeva MA, Eaton JS, Shadel GS. Loss of p53 causes mitochondrial DNA depletion and altered mitochondrial reactive oxygen species homeostasis. Biochim Biophys Acta. 2009; 1787:328-334. [PubMed: 19413947]

LeDoux SP, Shen C, Grishko VI, Fields PA, Gard AL, Wilson GL. Glial cell-specific differences in response to alkylation damage. Glia. 1998; 24:304-312. [PubMed: 9775981] 
Lefai E, Calleja M, Ruiz de Mena I, Lagina AT III, Kaguni LS, Garesse R. Overexpression of the catalytic subunit of DNA polymerase $\gamma$ results in depletion of mitochondrial DNA in Drosophila melanogaster. Mol Gen Genet. 2000; 264:37-46. [PubMed: 11016831]

Linder T, Park CB, Asin-Cayuela J, Pellegrini M, Larsson NG, Falkenberg M, Samuelsson T, Gustafsson CM. A family of putative transcription termination factors shared amongst metazoans and plants. Curr Genet. 2005; 48:265-269. [PubMed: 16193327]

Liu Y, Kao HI, Bambara RA. Flap endonuclease 1: a central component of DNA metabolism. Annu Rev Biochem. 2004; 73:589-615. [PubMed: 15189154]

Liu P, Qian L, Sung JS, de Souza-Pinto NC, Zheng L, Bogenhagen DF, Bohr VA, Wilson DM, Shen B, Demple B. Removal of oxidative DNA damage via FEN1-dependent long-patch base excision repair in human cell mitochondria. Mol Cell Biol. 2008; 28:4975-4987. [PubMed: 18541666]

Longley MJ, Prasad R, Srivastava DK, Wilson SH, Copeland WC. Identification of 5'-deoxyribose phosphate lyase activity in human DNA polymerase $\gamma$ and its role in mitochondrial base excision repair. Proc Natl Acad Sci USA. 1998; 95:12244-12248. [PubMed: 9770471]

Ma W, Sung HJ, Park JY, Matoba S, Hwang PM. A pivotal role for p53: balancing aerobic respiration and glycolysis. J Bioenerg Biomembr. 2007; 39:243-246. [PubMed: 17551815]

Maier D, Farr CL, Poeck B, Alahari A, Vogel M, Fischer S, Kaguni LS, Schneuwly S. Mitochondrial single-stranded DNA-binding protein is required for mitochondrial DNA replication and development in Drosophila melanogaster. Mol Biol Cell. 2001; 12:821-830. [PubMed: 11294889]

Martin M, Cho J, Cesare AJ, Griffith JD, Attardi G. Termination factor-mediated DNA loop between termination and initiation sites drives mitochondrial rRNA synthesis. Cell. 2005; 123:1227-1240. [PubMed: 16377564]

Martínez-Azorín F, Calleja M, Hernández-Sierra R, Farr CL, Kaguni LS, Garesse R. Over-expression of the catalytic core of mitochondrial DNA (mtDNA) polymerase in the nervous system of Drosophila melanogaster reduces median life span by inducing mtDNA depletion. J Neurochem. 2008; 105:165-176. [PubMed: 17999718]

Matsushima Y, Adán C, Garesse R, Kaguni LS. Drosophila mitochondrial transcription factor B1 modulates mitochondrial translation but not transcription or DNA copy number in Schneider cells. J Biol Chem. 2005; 280:16815-16820. [PubMed: 15749697]

Matsushima Y, Farr CL, Fan L, Kaguni LS. Physiological and biochemical defects in carboxylterminal mutants of mitochondrial DNA helicase. J Biol Chem. 2008; 283:23964-23971. [PubMed: 18593709]

Matsushima Y, Garesse R, Kaguni LS. Drosophila mitochondrial transcription factor B2 regulates mitochondrial DNA copy number and transcription in Schneider cells. 2004; 279:26900-26905.

Matsushima Y, Kaguni LS. Differential phenotypes of active site and human autosomal dominant progressive external ophthalmoplegia mutations in Drosophila mitochondrial DNA helicase expressed in Schneider cells. J Biol Chem. 2007; 282:9436-9444. [PubMed: 17272269]

Matsushima Y, Kaguni LS. Functional importance of the conserved N-terminal domain of the mitochondrial replicative DNA helicase. Biochim Biophys Acta. 2009; 1787:290-295. [PubMed: 19063859]

Metodiev MD, Lesko N, Park CB, Cámara Y, Shi Y, Wibom R, Hultenby K, Gustafsson CM, Larsson NG. Methylation of $12 \mathrm{~S}$ rRNA is necessary for in vivo stability of the small subunit of the mammalian mitochondrial ribosome. Cell Metab. 2009; 9:386-397. [PubMed: 19356719]

McCulloch V, Seidel-Rogol BL, Shadel GS. A human mitochondrial transcription factor is related to RNA adenine methyltransferases and bind S-adenosylmethionine. Mol Cell Biol. 2002; 22:11161125. [PubMed: 11809803]

Miller KE, Sheetz MP. Axonal mitochondrial transport and potential are correlated. J Cell Sci. 2004; 117:2791-2804. [PubMed: 15150321]

Morel F, Renoux M, Lachaume P, Alziari S. Bleomycin-induced double-strand breaks in mitochondrial DNA of Drosophila cells are repaired. Mutat Res. 2008; 637:111-117. [PubMed: 17825327]

Nishioka K, Ohtsubo T, Oda H, Fujiwara T, Kang D, Sugimachi K, Nakabeppu Y. Expression and differential intracellular localization of two major forms of human 8-oxoguanine DNA glycosylase 
encoded by alternatively spliced OGG1 mRNAs. Mol Biol Cell. 1999; 10:1637-1652. [PubMed: 10233168]

Palacino JJ, Sagi D, Goldberg MS, Krauss S, Motz C, Wacker M, Klose J, Shen J. Mitochondrial dysfunction and oxidative damage in parkin-deficient mice. J Biol Chem. 2004; 279:18614-18622. [PubMed: 14985362]

Park CB, Asin-Cayuela J, Cámara Y, Shi Y, Pellegrini M, Gaspari M, Wibom R, Hultenby K, Erdjument-Bromage H, Tempst P, Falkenberg M, Gustafsson CM, Larsson NG. MTERF3 is a negative regulator of mammalian mtDNA transcription. Cell. 2007; 130:273-285. [PubMed: 17662942]

Park J, Kim Y, Chung J. Mitochondrial dysfunction and Parkinson's disease genes: insights from Drosophila. Dis Model Mech. 2009; 2:336-340. [PubMed: 19553694]

Pesah Y, Pham T, Burgess H, Middlebrooks B, Verstreken P, Zhou Y, Harding M, Bellen H, Mardon G. Drosophila parkin mutants have decreased mass and cell size and increased sensitivity to oxygen radical stress. Development. 2004; 131:2183-2194. [PubMed: 15073152]

Pohjoismäki JLO, Goffart S, Tyynismaa H, Willcox S, Ide T, Kang D, Suomalainen A, Karhunen PJ, Griffith JD, Holt IJ, Jacobs HT. Human heart mitochondrial DNA is organized in complex catenated networks containing abundant four-way junctions and replication forks. J Biol Chem. 2009; 284:21446-21457. [PubMed: 19525233]

Polosa PL, Deceglie S, Roberti M, Gadaleta MN, Cantatore P. Contra-helicase activity of the mitochondrial transcription factor terminator mtDBP. Nuclei Acids Res. 2005; 33:3812-3820.

Pridgeon JW, Olzmann JA, Chin LS, Li L. PINK1 protects against oxidative stress by phosphorylating mitochondrial chaperone TRAP1. PLoS Biol. 2007; 5:e172. [PubMed: 17579517]

Radyuk SN, Michalak K, Rebrin I, Sohal RS, Orr WC. Effects of ectopic expression of Drosophila DNA glycosylases dOgg1 and RpS3 in mitochondria. Free Radical Biol Med. 2006; 41:757-764. [PubMed: 16895796]

Reyes A, Yang MY, Bowmaker M, Holt IL. Bidirectional replication initiates at sites throughout the mitochondrial genome of birds. J Biol Chem. 2005; 280:3242-3250. [PubMed: 15557283]

Roberti M, Bruni F, Polosa PL, Manzari C, Gadaleta MN, Cantatore P. MTERF3, the most conserved member of the mTERF-family, is a modular factor involved in mitochondrial protein synthesis. Biochem Biophys Acta. 2006; 1757:1199-1206. [PubMed: 16787637]

Roberti M, Fernandez-Silva P, Polosa LP, Fernandez-Vizarra E, Bruni F, Deceglie S, Montoya J, Gadaleta MN, Cantatore P. In vitro transcription termination activity of the Drosophila mitochondrial DNA-binding protein DmTTF. Biochem Biophys Res Commun. 2005; 331:357362. [PubMed: 15845400]

Roberti M, Polosa PL, Bruni F, Manzari C, Deceglie S, Gadaleta MN, Cantatore P. The MTERF family proteins: mitochondrial transcription regulators and beyond. Biochim Biophys Acta. 2009; 1787:303-311. [PubMed: 19366610]

Rothfuss O, Fisher H, Hasegawa T, Maisel M, Leitner P, Miesel F, Sharma M, Bornemann A, Berg D, Gasser T, Patenge N. Parkin protects mitochondrial genome integrity and supports mitochondrial DNA repair. Hum Mol Genet. 2009 Epub ahead of print, ddp327v1-ddp327.

Slupphaug G, Markussen FH, Olsen LC, Aasland R, Aarsaether N, Bakke O, Krokan HE, Helland DE. Nuclear and mitochondrial forms of human uracil-DNA glycosylase are encoded by the same gene. Nucleic Acids Res. 1993; 21:2579-2584. [PubMed: 8332455]

Spelbrink JN, Li FY, Tiranti V, Nikali K, Yuan QP, Tariq M, Wanrooij S, Garrido N, Comi G, Morandi L, Santoro L, Toscano A, Fabrizi GM, Somer H, Croxen R, Beeson D, Poulton J, Suomalainen A, Jacobs HT, Zeviani M, Larsson C. Human mitochondrial DNA deletions associated with mutations in the gene encoding Twinkle, a phage T7 gene 4-like protein localized in mitochondria. Nat Genet. 2001; 28:223-231. [PubMed: 11431692]

Srivastava S, Moraes CT. Double-strand breaks of mouse muscle mtDNA promote large deletions similar to multiple mtDNA deletions in humans. Hum Mol Genet. 2005; 14:893-902. [PubMed: 15703189]

Tang Y, Manfredi G, Hirano M, Schon EA. Maintenance of human rearranged mitochondrial DNAs in long-term cultured transmitochondrial cell lines. Mol Biol Cell. 2000; 11:2349-2358. [PubMed: 10888673] 
Thömmes P, Farr CL, Marton RF, Kaguni LS, Cotterill S. Mitochondrial single-stranded DNA-binding protein from Drosophila embryos. Physical and biochemical characterization. J Biol Chem. 1995; 270:21137-21143. [PubMed: 7673145]

Thompson LV. Oxidative stress, mitochondria and mtDNA-mutator mice. Exp Gerontol. 2006; 41:1220-1222. [PubMed: 17126516]

Thyagarajan B, Padua RA, Campbell C. Mammalian mitochondria possess homologous DNA recombination activity. J Biol Chem. 1996; 271:27536-27543. [PubMed: 8910339]

Tomkinson AE, Bonk RT, Linn S. Mitochondrial endonuclease activities specific for apurinic/ apyrimidinic sites in DNA from mouse cells. J Biol Chem. 1988; 263:12532-12537. [PubMed: 2457585]

Trifunovic A, Wredenberg A, Falkenberg M, Spelbrink JN, Rovio AT, Bruder CE, Bohlooly-Y M, Gidlöf S, Oldfors A, Wibom R, Törnell J, Jacobs HT, Larsson NG. Premature ageing in mice expressing defective mitochondrial DNA polymerase. Nature. 2004; 429:417-423. [PubMed: 15164064]

Tyynismaa H, Mjosund KP, Wanrooij S, Lappalainen I, Ylikallio E, Jalanko A, Spelbrink JN, Paetau A, Suomalainen A. Mutant mitochondrial helicase Twinkle causes multiple mtDNA deletions and a late-onset mitochondrial disease in mice. Proc Natl Acad Sci USA. 2005; 102:1768717692. [PubMed: 16301523]

Vermulst M, Bielas JH, Kujoth GC, Ladiges WC, Rabinovitch PS, Prolla TA, Loeb LA. Mitochondrial point mutations do not limit the natural lifespan of mice. Nat Genet. 2007; 39:540-543. [PubMed: 17334366]

Vermulst M, Wanagat J, Kujoth GC, Bielas JH, Rabinovitch PS, Prolla TA, Loeb LA. DNA deletions and clonal mutations drive premature ageing in mitochondrial mutator mice. Nat Genet. 2008; 40:392-394. [PubMed: 18311139]

Vousden KH, Ryan KM. p53 and metabolism. Nat Rev Cancer. 200910.1038/nrc2715

Wallace DC. A mitochondrial paradigm of metabolic and degenerative diseases, ageing, and cancer: a dawn for evolutionary medicine. Annu Rev Gen. 2005; 39:359-407.

Wallace DC. Mitochondria as chi. Genetics. 2008; 179:727-735. [PubMed: 18558648]

Wallace DC, Fan WW. The pathophysiology of mitochondrial disease as modeled in the mouse. Genes Dev. 2009; 23:1714-1736. [PubMed: 19651984]

Wanrooij S, Goffart S, Pohjoismäki JL, Yasukawa T, Spelbrink JN. Expression of catalytic mutants of the mtDNA helicase Twinkle and polymerase POLG causes distinct replication stalling phenotypes. Nucleic Acids Res. 2007; 35:3238-3251. [PubMed: 17452351]

Wenz T, Luca C, Torraco A, Moraes CT. mTERF2 regulates oxidative phosphorylation by modulating mtDNA transcription. Cell Metab. 2009; 9:499-511. [PubMed: 19490905]

Wong TS, Rajagopalan S, Freund SM, Rutherford TJ, Andreeva A, Townsley FM, Petrovich M, Loakes D, Fersht AR. Biophysical characterizations of human mitochondrial transcription factor A and its binding to tumor suppressor p53. Nucleic Acids Res. 2009a10.1093/nar/gkp750

Wong TS, Rajagopalan S, Townsley FM, Freund SM, Petrovich M, Loakes D, Fersht AR. Physical and functional interactions between human mitochondrial single-stranded DNA-binding protein and tumor suppressor p53. Nucleic Acids Res. 2009b; 37:568-581. [PubMed: 19066201]

Yang MY, Bowmaker M, Reyes A, Vergani L, Angeli P, Gringeri E, Jacobs HT, Holt IJ. Biased incorporation of ribonucleotides on the mitochondrial L-strand accounts for apparent strandasymmetric DNA replication. Cell. 2002; 111:495-505. [PubMed: 12437923]

Yasukawa T, Reyes A, Cluett TJ, Yang MY, Bowmaker M, Jacobs HT, Holt IJ. Replication of vertebrate mitochondrial DNA entails transient ribonucleotide incorporation throughout the lagging strand. EMBO J. 2006; 25:5358-5371. [PubMed: 17066082]

Yoshida Y, Izumi H, Torigoe T, Ishiguchi H, Itoh H, Kang D, Kohno K. p53 physically interacts with mitochondrial transcription factor A and differentially regulates binding to damaged DNA. Cancer Res. 2003; 63:3729-3734. [PubMed: 12839966]

Zhen L, Zhou M, Guo Z, Lu H, Qian L, Dai H, Qiu J, Yakubovskaya E, Bogenhagen DF, Demple B, Shen B. Human DNA2 is a mitochondrial nuclease/ helicase for efficient processing of DNA replication and repair intermediates. Mol Cell. 2008; 32:325-336. [PubMed: 18995831] 
Zsurka G, Kraytsberg Y, Kudina T, Kornblum C, Elger CE, Khrapko K, Kunz WS. Recombination of mitochondrial DNA in skeletal muscle of individuals with multiple mitochondrial DNA heteroplasmy. Nat Genet. 2005; 37:873-877. [PubMed: 16025113]

\section{The abbreviations used are}

$\begin{array}{ll}\text { mIDNA } & \text { mitochondrial DNA } \\ \text { OXPHOS } & \text { oxidative phosphorylation system } \\ \text { ROS } & \text { reactive oxygen species } \\ \text { COX } & \text { cytochrome } c \text { oxidase } \\ \text { PD } & \text { Parkinson's disease } \\ \text { RIs } & \text { replication intermediates } \\ \text { NCR } & \text { non-coding region } \\ \text { RITOLS } & \text { RNA incorporated throughout the lagging strand } \\ \text { T7 gp4 } & \text { bacteriophage T7 gene 4 primase-helicase } \\ \text { BER } & \text { base excision repair } \\ \text { OGG1 } & \text { 8-oxoguanine glycosylase } \\ \text { NO } & \text { nitric oxide } \\ \text { DSB } & \text { double-strand breaks } \\ \text { HR } & \text { homologous recombination } \\ \text { NHEJ } & \text { non-homologous end-joining }\end{array}$



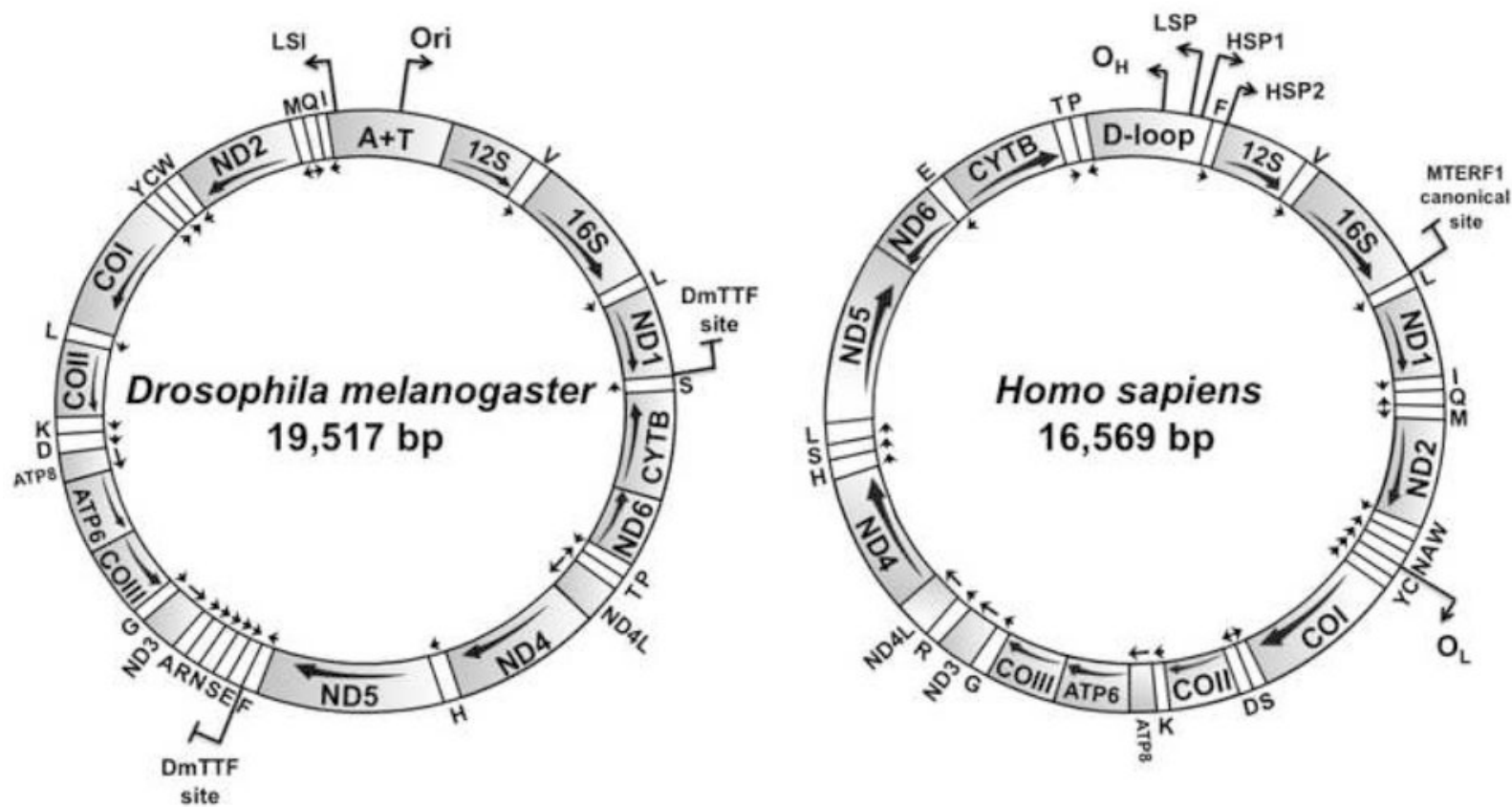

Figure 1.

Schematic representation of Drosophila and human mtDNA. These genomes represent a typical gene organization found in insect and mammalian mtDNAs, respectively. The major non-coding regions of mtDNA, denoted as "A+T" for Drosophila and "D-loop" for human, are the regions where most sequence variation is found among animal species. The arrows below each gene indicate the direction of transcription. tRNA genes are indicated by oneletter symbols, and the $12 \mathrm{~S}$ and $16 \mathrm{~S}$ rRNA genes appear as $12 \mathrm{~S}$ and $16 \mathrm{~S}$, respectively. In the fruitfly genome: Ori, origin of replication (initiation of leading strand synthesis); LSI, initiation of lagging strand synthesis, according to Goddard and Wolstenholme (1980). In the human genome: $\mathrm{O}_{\mathrm{H}}$, origin of heavy (leading) strand synthesis; $\mathrm{O}_{\mathrm{L}}$, origin of light (lagging) strand synthesis, according to the strand-displacement model of mtDNA replication; LSP, light strand promoter; HSP1 and 2, heavy strand promoters 1 and 2. Only the canonical binding site for MTERF1 is shown; for more details on other binding sites, see the text and Hyvärinen et al. (2007). 


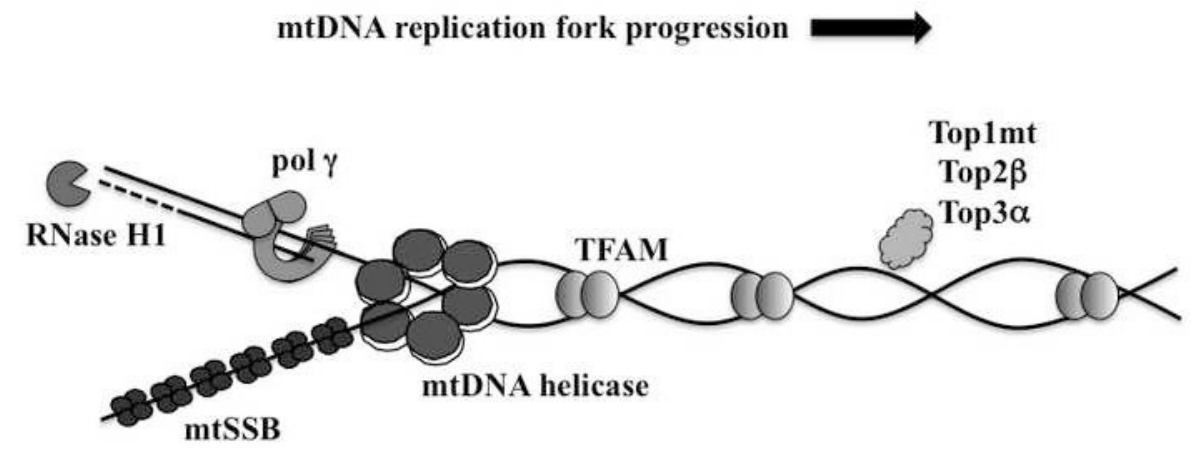

Figure 2.

Factors involved in mtDNA replication in animals. Solid lines represent DNA, and the dashed line represents RNA. The diagram is not to scale, nor is it meant to depict protein or DNA structure, or specific protein-protein interactions. See Table I and the text for descriptions of the factors. 
BER pathways in mitochondria

single-nucleotide

UDG

OGG1

MUTYH

NTH

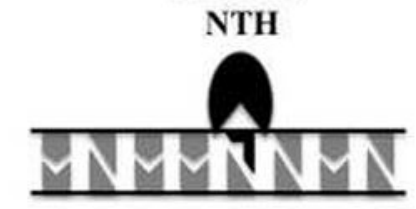

$\underset{\text { base }}{\text { damaged }}$

MNMN

$\mathbf{1}$ long-patch

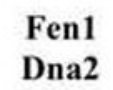

Fen1

Dna2
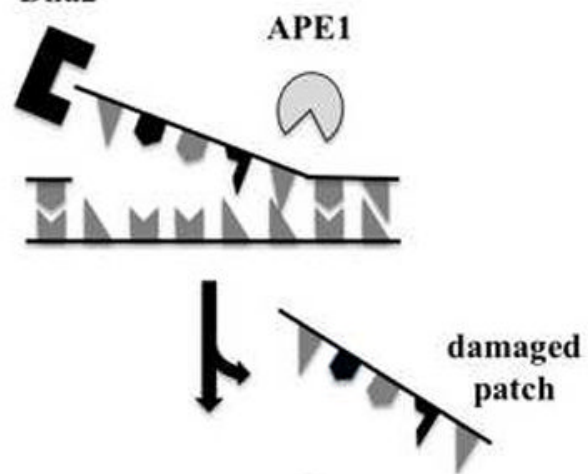

MNMMAN

pol $\gamma$

ligase

III

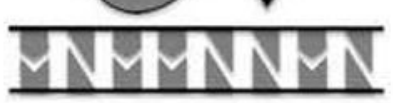

Figure 3.

Possible pathways for post-replicative mtDNA repair. Both single-nucleotide (left) and longpatch (right) BER are believed to end with the concerted action of pol $\gamma$ and DNA ligase III. The diagram is not to scale, nor is it meant to depict protein or DNA structure, or specific protein-protein interactions. See Table I and the text for descriptions of the factors. 


\section{mitochondrial transcription}

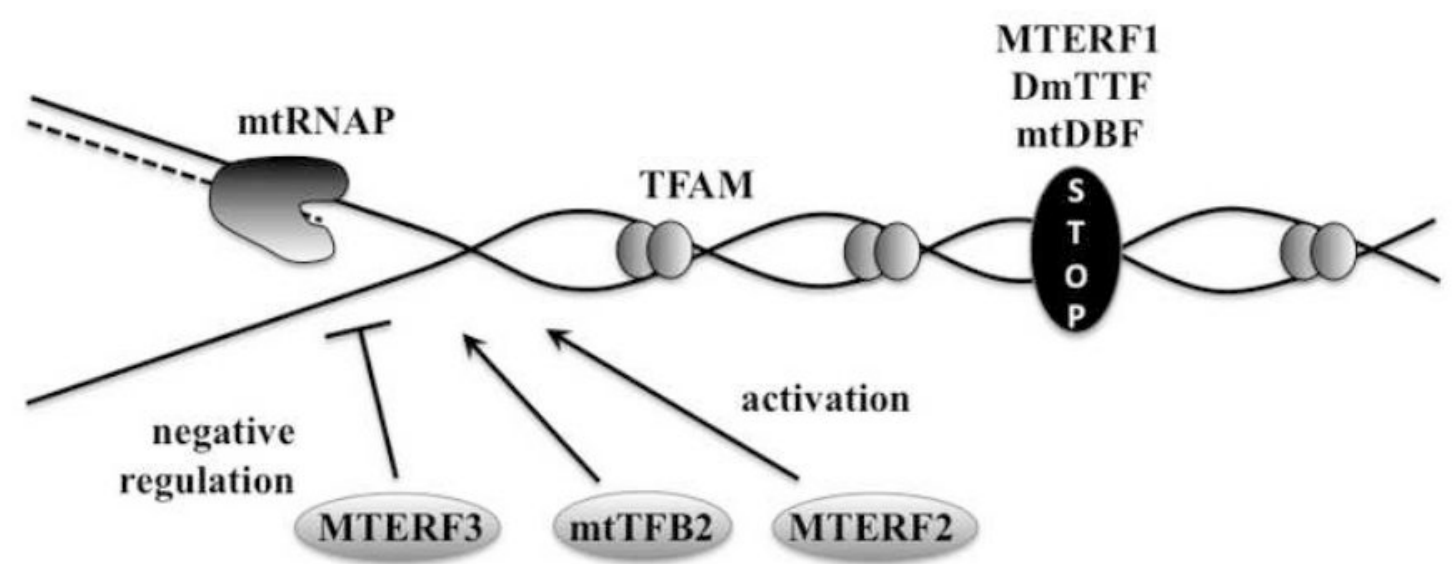

Figure 4.

Overview of transcription in animal mitochondria and the proteins involved in the process. Solid lines represent DNA, and the dashed line represents RNA. The diagram is not to scale, nor is it meant to depict protein or DNA structure, or specific protein-protein interactions. See Table I and the text for descriptions of the factors. 
Table 1

Proteins involved in mtDNA transactions and their functions

\begin{tabular}{|c|c|c|}
\hline Transaction & Protein & Function \\
\hline \multirow[t]{8}{*}{ Replication } & TFAM $^{*}$ & Nucleoid organization; compaction and packing of mtDNA \\
\hline & $\operatorname{pol} \gamma$ & DNA polymerase and exonuclease \\
\hline & mtDNA helicase & dsDNA unwinding \\
\hline & $\mathrm{mtSSB}$ & ssDNA-binding; stimulation of pol $\gamma$ and mtDNA helicase activities \\
\hline & RNase H1 & primer formation and/ or processing \\
\hline & Top1mt & vertebrate topoisomerase type IB \\
\hline & Тор2 $\beta$ & topoisomerase type II \\
\hline & Top3 $\alpha$ & topoisomerase type IA \\
\hline \multirow[t]{11}{*}{ Repair/ recombination } & $\operatorname{pol} \gamma$ & exonuclease, lyase and gap-filling \\
\hline & UDG & uracil DNA glycosylase \\
\hline & OGG1 & 8-oxoguanine DNA glycosylase and lyase activities \\
\hline & MUTYH & MutY glycosylase \\
\hline & NTH & thymine glycol glycosylase \\
\hline & APE1 & apurinic/ apyrimidinic endonuclease \\
\hline & DNA ligase III & nick sealing \\
\hline & Fen1 & flap endonuclease \\
\hline & Dna2 & flap endonuclease \\
\hline & $\mathrm{p} 53$ & exonuclease; interactions with pol $\gamma$, TFAM and mtSSB \\
\hline & parkin & E3-ligase ${ }^{* *}$ \\
\hline \multirow[t]{7}{*}{ Transcription } & mtRNAP & RNA polymerase \\
\hline & mtTFB2 & activation of mitochondrial transcription \\
\hline & DmTTF & regulation of mitochondrial transcription termination in Drosophila \\
\hline & $\mathrm{mtDBP}$ & regulation of mitochondrial transcription termination in sea urchin \\
\hline & MTERF1 & regulation of mitochondrial transcription termination/ replication pausing in humans \\
\hline & MTERF2 & activation of mitochondrial transcription \\
\hline & MTERF3 & negative regulation of mitochondrial transcription \\
\hline
\end{tabular}

* because TFAM functions in packaging and compaction of mtDNA in mitochondrial nucleoids, it is likely involved in all mtDNA transactions. $* *$

the mechanism associating this activity with mtDNA repair is not clear (see text for more detail). 